\title{
Traps Formation and Characterization in Long-Term Energy Storing Lu203:Pr,Hf Luminescent Ceramics
}

\begin{tabular}{|r|l|}
\hline Journal: & The Journal of Physical Chemistry \\
\hline Manuscript ID: & Draft \\
\hline Manuscript Type: & Article \\
\hline Date Submitted by the Author: & n/a \\
\hline Complete List of Authors: & $\begin{array}{l}\text { Wiatrowska, Aneta; University of Wroclaw, Faculty of Chemistry } \\
\text { Zych, Eugeniusz; University of Wroclaw, Faculty of Chemistry }\end{array}$ \\
\hline
\end{tabular}

\section{SCHOLARONE \\ Manuscripts}




\title{
Traps Formation and Characterization in Long-Term Energy Storing $\mathrm{Lu}_{2} \mathrm{O}_{3}: \mathrm{Pr}$,Hf Luminescent Ceramics
}

\author{
ANETA WIATROWSKA ${ }^{1}$, EUGENIUSZ ZYCH ${ }^{1,2} *$ \\ ${ }^{1}$ Faculty of Chemistry, University of Wroclaw, 14 F. Joliot-Curie Street \\ 50-383 Wroclaw, Poland \\ ${ }^{2}$ Wroclaw Research Centre EIT+, 147/149 Stablowicka Street \\ 54-066 Wroclaw, Poland
}

KEYWORDS. Storage phosphor, defects, traps, lutetium oxide

\begin{abstract}
Sintered ceramics of $\mathrm{Lu}_{2} \mathrm{O}_{3}: \operatorname{Pr}$,Hf storage phosphor were prepared and their spectroscopic properties were evaluated. It was shown that during irradiation with X-rays as well as with short UV radiation, the material was able to accumulate energy, which could thereafter be recovered by thermal stimulation in the range of approximately $20-450{ }^{\circ} \mathrm{C}$. The glow curve consisted of three bands peaking around $130{ }^{\circ} \mathrm{C}, 250^{\circ} \mathrm{C}$ and $340{ }^{\circ} \mathrm{C}$, and each of them contained two overlapping components. The thermoluminescence was found to follow the first-order kinetics mechanism and the activation energies of the traps derived from the glow curve fitting covered the range of about $0.8-2.1 \mathrm{eV}$. Frequency factors of the traps were also calculated and were mostly found to exceed the Debye frequency by 3-4 orders of magnitude indicating a
\end{abstract}


complex mechanism of the process. The fading measured nine months after the material irradiation revealed only about $30 \%$ loss of the thermoluminescence intensity. Controlled thermal annealing at defined temperatures as well as optical stimulation with infrared $(980 \mathrm{~nm}$, $780 \mathrm{~nm})$ or violet photons $(400 \mathrm{~nm})$ proved that it is possible to recover the stored energy either from all traps simultaneously or just from a fraction of them leaving energy stored in the others unaffected. Irradiation with X-rays altered absorption spectrum inducing a new broad band component covering near-UV-blue-green region which perfectly harmonized with a significant decrease of absorption efficiency in the short-UV wavelengths range of $\mathrm{f} \rightarrow \mathrm{d} \operatorname{Pr}^{3+}$ transitions. These variations were fully reversible by means of thermal or UV (400 nm) bleaching. Defects responsible for the energy storing were identified. Long term energy storing traps giving the high temperature TL components were assigned to the presence of $\mathrm{Hf}(\mathrm{IV})$ (electron trap), which replaced $\mathrm{Lu}(\mathrm{III})$ in the host $\left(\mathrm{TL}\right.$ around $250{ }^{\circ} \mathrm{C}$ ) and $\mathrm{Pr}^{3+}$ activator trapping a hole (TL around $\left.340{ }^{\circ} \mathrm{C}\right)$. The good long term stability of the thermoluminescence signal and high efficiency of absorption of ionizing radiation due to a very high density of the lutetia host may make the $\mathrm{Lu}_{2} \mathrm{O}_{3}: \mathrm{Pr}$,Hf composition an interesting material for high energy particles dosimetry.

\section{INTRODUCTION}

Mechanisms of various processes related to photoluminescence have been well understood in $\mathrm{XX}$ century and now we can benefit from that knowledge anticipating spectroscopic properties of various compositions and consequently we can quite deliberately design new phosphors. However, persistent and storage phosphors are not so well understood yet. ${ }^{1-4}$ These materials can store energy trapping excited carriers in defects for hours (persistent phosphors) or days and even years (storage phosphors). Fortunately, recently we got an important tool to foresee and predict properties of such materials too, as Dorenbos combined the possibility of positioning the 
electronic levels of lanthanides ions within a host forbidden energy gap with the prediction of the trap depths created by these ions. ${ }^{5-9}$ First proofs of the applicability of this approach have recently been reported. ${ }^{7-9}$ However, there are materials which store energy and produce efficient thermoluminescence well above room temperature due to traps created by different types of impurities, d-elements or closed-shell elements. The old, well known group of ZnS-based persistent phosphors is a good example of such a situation. ${ }^{10,11}$

In recent years, exploiting $\mathrm{Lu}_{2} \mathrm{O}_{3}$ host to make luminescent materials we found a group of compositions able to show a surprisingly efficient, hours-lasting persistent luminescence $\left(\mathrm{Lu}_{2} \mathrm{O}_{3}: \mathrm{Tb}, \mathrm{M} \text {, where } \mathrm{M}=\mathrm{Ca}, \mathrm{Sr}, \mathrm{Ba}\right)^{12,13}$ or being able to store energy even more permanently in yet deeper traps $\left(\mathrm{Lu}_{2} \mathrm{O}_{3}: \mathrm{Tb}, \mathrm{Hf}\right) .{ }^{14,15} \mathrm{We}$ showed that introducing a spectroscopically inert (closed-shell), aliovalent co-dopant and adjusting the parameters of materials fabrication, formation of traps able to store energy can thus be accomplished and their properties can be controlled.

First, scant information on energy storing in $\mathrm{Lu}_{2} \mathrm{O}_{3}: \mathrm{Pr}$, Hf ceramics we gave previously in a conference paper. ${ }^{15}$ Here we present a comprehensive picture of the properties of $\mathrm{Lu}_{2} \mathrm{O}_{3}: \mathrm{Pr}, \mathrm{Hf}$ as a storage phosphor with bright red luminescence due to $\operatorname{Pr}^{3+}$ dopant. We also present and discuss the effect of $\mathrm{Hf}$ co-dopant on shaping the material behavior. The $\mathrm{Lu}_{2} \mathrm{O}_{3}: \mathrm{Pr}$, Hf ceramics can store energy acquired either upon irradiation with X-Rays or high-energy UV photons. Due to its high density $\left(9.4 \mathrm{~g} / \mathrm{cm}^{3}\right)$ and high absorption coefficient for $\mathrm{X}$ - and $\gamma$-Rays $\mathrm{Lu}_{2} \mathrm{O}_{3}$ :Pr, Hf might be considered a good candidate for dosimeters to monitor such particles dosage in some circumstances. ${ }^{16}$ Yet, at present, the understanding of the co-operative effect of the two codopants in transferring lutetia into efficient storage phosphor is most important and truly intriguing. 


\section{SAMPLE PREPARATION}

$\mathrm{Lu}_{2} \mathrm{O}_{3}: \mathrm{Pr}$,Hf sintered ceramics were made by high-temperature sintering of raw powders prepared by the Pechini technique. ${ }^{17}$ To prepare the latter, lutetium(III) nitrate pentahydrate $\left(\mathrm{Lu}\left(\mathrm{NO}_{3}\right)_{3} \cdot 5 \mathrm{H}_{2} \mathrm{O}, 4 \mathrm{~N}\right)$, praseodymium(III) nitrate hexahydrate $\left(\operatorname{Pr}\left(\mathrm{NO}_{3}\right)_{3} \cdot 6 \mathrm{H}_{2} \mathrm{O}, 4 \mathrm{~N}\right)$, and hafnium(IV) chloride $\left(\mathrm{HfCl}_{4}, 3 \mathrm{~N}\right)$ were used. Their stoichiometric amounts were dissolved in $2 \mathrm{M}$ citric acid (HOOC-CH $\left.2-\mathrm{C}(\mathrm{OH})(\mathrm{COOH})-\mathrm{CH}_{2}-\mathrm{COOH}\right)$ to complex the metal ions. Next, some ethylene glycol $\left(\mathrm{C}_{2} \mathrm{H}_{4}(\mathrm{OH})_{2}\right)$ was added. The resultant solution was condensed at $80{ }^{\circ} \mathrm{C}$ and then the temperature was slowly increased up to $700{ }^{\circ} \mathrm{C}$, which appeared sufficient to burn off the organics. For sintering, such a raw powder was pressed into a pellet $8 \mathrm{~mm}$ in diameter under the load of 4 tons. Such a pellet was transferred into a tube furnace and was heated at $1700{ }^{\circ} \mathrm{C}$ for 5 hours under a reducing atmosphere - a mixture of $75 \% \mathrm{~N}_{2}-25 \% \mathrm{H}_{2}$. The concentrations of praseodymium and hafnium in $\mathrm{Lu}_{2} \mathrm{O}_{3}: \mathrm{Pr}$, Hf ceramics reported here were $0.05 \%$ and $0.1 \%$, respectively. During the course of our research such a composition was found to give the most intense thermoluminescence. Details of the composition optimization are not presented in this paper.

\section{EXPERIMENTAL METHODS}

The samples' phase purity was evaluated by powder X-Ray diffraction technique using D8 Advance X-Ray diffractometer from Bruker with Nickel-filtered $\mathrm{Cu} \mathrm{K}_{\alpha 1}$ radiation $(\lambda=1.540596$ $\AA$ ). The measurement was performed in the range of $2 \theta=10-120$ degree with the step of $2 \theta=0.00857$ degree and the counting time of $0.2 \mathrm{~s}$ per point.

The luminescence excitation spectra were measured in the range of 250-600 nm at room temperature with an FSL 920 Spectrometer from Edinburg Instruments using a 450W Xenon 
lamp as an excitation source. These spectra were recorded on freshly prepared specimen as well as on material with different history: treated with X-rays, and further irradiated with $400 \mathrm{~nm}$ radiation. The $632 \mathrm{~nm}$ luminescence decay traces at elevated temperatures $\left(25-500{ }^{\circ} \mathrm{C}\right)$ were measured using the third harmonic $(355 \mathrm{~nm})$ of the YAG:Nd laser as an excitation source and PMT R928P side-on type photomultiplier as a detector. Emission and excitation spectra (in the range of 50-333 nm) were also recorded at room temperature (RT) using synchrotron radiation at the Superlumi station of Hasylab (DESY, Hamburg, Germany). The sodium salicylate was used as a standard to correct excitation spectra for the incident radiation intensity. Emission spectra were corrected for the recording system characteristics. Absorption spectra were obtained using Cary 5000 SCAN UV-VIS-NIR spectrophotometer. Thermoluminescence (TL) glow curves were recorded using a custom-made temperature controller with linear heating rate in the range of $20-500{ }^{\circ} \mathrm{C}$ and using Ocean Optics HR2000 CG spectrometer operating under Spectra Suit dedicated software. The light produced upon heating was collected with a 74-UV lens coupled to a QP600-1-SR waveguide which transferred it to the detector. TL glow curves were recorded with the counting time of $1 \mathrm{~s}$ and monitoring the intensity of the $\operatorname{Pr}^{3+}$ red emission band around $630 \mathrm{~nm}$. The setup allowed to record full spectra in the range of 200-1100 nm, simultaneously. The typical heating rate was $4.8^{\circ} \mathrm{C} / \mathrm{s}$. Additionally, a set of glow curves was recorded varying the heating rate in the range of $1-8{ }^{\circ} \mathrm{C} / \mathrm{s}$. The glow curves were deconvoluted into TL components using GlowFit software kindly supplied by Dr. M. Puchalska from Cracow, Poland. ${ }^{18}$ White X-Rays from a Cu lamp of DRON-1 diffractometer were used for irradiation of the materials prior to thermoluminescence and optically stimulated luminescence (OSL) experiments. Only to monitor fading of the TL signal irradiations were performed with $254 \mathrm{~nm}$, as it allowed to control the dosage to a much higher degree than using an X-ray machine. The 
OSL measurements were done upon stimulation with $980 \mathrm{~nm}$ or $780 \mathrm{~nm}$ radiation from $1 \mathrm{~mW}$ diode lasers and with $400 \mathrm{~nm}$ radiation from a semiconductor diode. The Kröger-Vink notation of defects was used throughout the paper. ${ }^{19,20}$

\section{RESULTS}

All XRD patterns perfectly agreed with the cubic structure of $\mathrm{Lu}_{2} \mathrm{O}_{3}$ (ICSD\#40471), ${ }^{21}$ indicating that the synthesized products are crystalline and single phase at least to the detection limit of this technique. These findings shall not be presented here, as analogous results for $\mathrm{Lu}_{2} \mathrm{O}_{3}$ powders and ceramics were frequently published in recent years. ${ }^{22-24}$

Figure 1 presents TL glow curves of undoped $\mathrm{Lu}_{2} \mathrm{O}_{3}$, singly doped $\mathrm{Lu}_{2} \mathrm{O}_{3}: 0.05 \% \operatorname{Pr}$, $\mathrm{Lu}_{2} \mathrm{O}_{3}: 0.1 \% \mathrm{Hf}$ and doubly activated $\mathrm{Lu}_{2} \mathrm{O}_{3}: 0.05 \% \mathrm{Pr}, 0.1 \% \mathrm{Hf}$ ceramics measured immediately after irradiation of the materials with X-Rays. In the undoped lutetia as well as in the composition containing solely Hf dopant, no TL signal was observed. Single activation with $\operatorname{Pr}$ allowed getting TL located around $340{ }^{\circ} \mathrm{C}$ of barely recordable intensity. Simultaneous co-doping with Pr and Hf changed the situation completely and a very intense red thermoluminescence appearing at three different ranges of temperatures, around $135{ }^{\circ} \mathrm{C}, 250{ }^{\circ} \mathrm{C}$ and $340{ }^{\circ} \mathrm{C}$, was seen. Hence, it is clearly a cooperative effect of both Pr and Hf introduced into the $\mathrm{Lu}_{2} \mathrm{O}_{3}$ host lattice, which transforms the composition into efficient storage phosphor.

Figure 2 presents excitation spectra of the $610 \mathrm{~nm}$ and $631.5 \mathrm{~nm}$ emissions together with photoluminescence and thermoluminescence (at $250{ }^{\circ} \mathrm{C}$ ) spectra of $\mathrm{Lu}_{2} \mathrm{O}_{3}: 0.05 \% \mathrm{Pr}, 0.1 \% \mathrm{Hf}$ ceramics. The excitation spectra of the $\operatorname{Pr}^{3+}$ emissions is dominated by broad bands around 300 nm resulting from the $4 \mathrm{f} \rightarrow 5 \mathrm{~d}$ absorption of $\operatorname{Pr}^{3+}$ as already identified $\mathrm{in}^{25}$. It is well seen that monitoring the two different wavelengths $(610 \mathrm{~nm}$ and $631.5 \mathrm{~nm})$ quite noticeable differences in 
the ratio of the $\mathrm{f} \rightarrow \mathrm{d}$ components around $280 \mathrm{~nm}$ and $320 \mathrm{~nm}$ appear. This indicates that $\operatorname{Pr}$ occupies both $\mathrm{C}_{2}$ and $\mathrm{C}_{3 \mathrm{i}}$ sites offered by the lutetia host. ${ }^{25}$ At wavelengths shorter than approximately $220 \mathrm{~nm}$ the incident photons are absorbed by the host lattice through its fundamental absorption band. The narrow peak at $218 \mathrm{~nm}$ reflects presumably the formation of free exciton while at yet shorter wavelengths the energy is sufficient to raise electrons to the conduction band and thus forming free carriers, electrons and holes. Analogous effects in excitation spectra were observed and analyzed in detail for $\mathrm{Lu}_{2} \mathrm{O}_{3}: \mathrm{Eu}^{26}$ Under the excitation into the $4 \mathrm{f}^{2} \rightarrow 4 \mathrm{f} 5 \mathrm{~d}$ transition, the ceramics produce strong luminescence in the range of $590-700 \mathrm{~nm}$ and much less intense emission covering the range of $700-770 \mathrm{~nm}$. Both structures were assigned by De Mello Donega to the ${ }^{1} \mathrm{D}_{2} \rightarrow{ }^{3} \mathrm{H}_{4}$ and ${ }^{1} \mathrm{D}_{2} \rightarrow{ }^{3} \mathrm{H}_{5}$ transitions, respectively. ${ }^{25}$ Practically, no emission from the higher positioned ${ }^{3} \mathrm{P}_{0}$ level is observed. The TL emission spectrum (blue line, right hand side in Figure 2) appears very similar to the PL (black line). Some small variations in relative intensities of the components may well result from the different temperatures of both experiments as well as from altered ratio of the emissions from $\operatorname{Pr}\left(\mathrm{C}_{2}\right)$ and $\operatorname{Pr}\left(\mathrm{C}_{3 \mathrm{i}}\right)$ ions.

The $\mathrm{Lu}_{2} \mathrm{O}_{3}: \mathrm{Pr}$,Hf ceramics showed some small red afterglow, both after exposure into short UV radiation $(<330 \mathrm{~nm})$ and into X-Rays. Figure 3 presents TL glow curve recorded in the range of 323-773 K (50-500 $\left.{ }^{\circ} \mathrm{C}\right)$ and its deconvolution into six components. The experimental glow curve contains three main bans peaking around $137{ }^{\circ} \mathrm{C}, 250{ }^{\circ} \mathrm{C}$ and $340{ }^{\circ} \mathrm{C}$. All the bands are asymmetrically broadened from the low-temperature side to some extent. Assuming the firstorder kinetics, the whole glow curve could be deconvoluted into six components, according to eq 1:

$I(t)=-\frac{d n}{d t}=s n \exp \left(-\frac{E}{k T}\right)$ 
where $I(t)$ corresponds to TL intensity in photons per second at time $t$ during the heating, $s\left(\mathrm{~s}^{-1}\right)$ is a frequency factor (with typical values being in the range of $10^{12}-10^{14} \mathrm{~s}^{-1}$, the Debye frequency) and $E$ stands for the trap depth. ${ }^{27}$ The parameters of the six traps derived from the fitting with the first-order kinetics are listed in Table 1.

One can note that the highest-temperature TL glow band has the most symmetric shape. Consequently, one could consider that it results from a second-order kinetic process. ${ }^{1}$ Indeed, we were able to make a good accuracy fit in which this constituent of the glow curve could be reproduced as one component of second-order kinetics with $E=2.25 \mathrm{eV}$ and $s=1 \times 10^{11} \mathrm{~s}^{-1}$. However, the later results, especially the variations of the TL glow bands with varying doses, which will be presented in Figure 4, disproved such supposition and therefore we consider the high temperature TL glow component to result from two traps of first-order kinetics.

Traps \#1 contributes almost exclusively to the TL band peaking around $135^{\circ} \mathrm{C}$. Trap $\# 2$ gives $\mathrm{TL}$ of negligible intensity around $180^{\circ} \mathrm{C}$. Traps \#3 and \#4 compose together the TL band around $250{ }^{\circ} \mathrm{C}$, which is the most intense among the three, and finally carriers from traps \#5 and \#6 are responsible for the TL appearing around $340{ }^{\circ} \mathrm{C}$. Hence, in fact each of the three bands (and certainly the two located at higher temperatures) seems to be composed of two components representing two traps characterized by pretty close depths (see Table 1). This might be connected with the structure of the $\mathrm{Lu}_{2} \mathrm{O}_{3}$ host material in which two symmetry sites, $\mathrm{C}_{2}$ and $\mathrm{C}_{3 \mathrm{i}}$, for metal cations are present. ${ }^{25,26}$ This is, however, just an intuitive suspicion at present, having no real experimental support.

Frequency factor is a parameter whose value may give some indications on the mechanism of the TL process. ${ }^{27}$ In a typical TL course, when trapped electron is moved to conduction band and after some diffusion falls into the emitting center to radiatively recombine there, $s$ is on the order 
of $10^{13} \mathrm{~s}^{-1}$. The data in Table 1 prove that in the case of $\mathrm{Lu}_{2} \mathrm{O}_{3}: \operatorname{Pr}$, Hf the values of frequency factors for most of the traps are by about 3-4 orders of magnitude larger. Noticeably higher frequency factors are usually connected with a more complex mechanism of the process. Mandowski showed that in such cases cascade detrapping may appear a probable mechanism. ${ }^{28}$ Enhanced values of the frequency factor may also result from parallel happening courses. On the other hand, in the case of strongly overlapping TL bands the parameters from fits should not be treated as definitive. $^{27}$

Knowing the trap depth and its associated frequency factor an average time a carrier spends in the trap $(\tau)$ can be calculated according to eq $2^{27}$ :

$\tau=s^{-1} \exp \left(\frac{E}{k T}\right)$

These values are also listed in Table 1 and show that traps producing the TL bands at $250{ }^{\circ} \mathrm{C}$ and $340{ }^{\circ} \mathrm{C}$ (\#3-6) should keep the trapped carriers for milliards of years. Only carriers in the two traps producing the TL band below $200{ }^{\circ} \mathrm{C}$ are able to escape them within hours, which indeed takes place as the material shows visible afterglow for some time. After a few hours in darkness, this component is no longer seen in the TL glow curve, as will be presented later.

TL glow curves of $\mathrm{Lu}_{2} \mathrm{O}_{3}: 0.05 \% \mathrm{Pr}, 0.1 \% \mathrm{Hf}$ ceramics as a function of irradiation time with $\mathrm{X}$ Rays are presented in Figure 4a. The band positions (maxima) occur perfectly at the same temperatures, which is one of the criteria proving the first-order kinetics. ${ }^{27}$ This result further supports the conclusions from the glow curve deconvolution presented above. Independently on the irradiation time (the dose) all the taps contribute to the thermoluminescence. However, the least intense structure around $135{ }^{\circ} \mathrm{C}$ saturates within first few minutes of the irradiation, while the two others located at higher temperatures seem to follow the linear increase of intensity (in $\log -\log$ scale) at least within the first 60 minutes of irradiation, see Figure $4 \mathrm{~b}$. 
Figure 5 compares the TL glow curves of the $\mathrm{Lu}_{2} \mathrm{O}_{3}: 0.05 \% \mathrm{Pr}, 0.1 \% \mathrm{Hf}$ material recorded with different delay time after UV irradiation. It is clear that 4 hours is enough to lose all the energy stored in traps producing the TL signal around $135^{\circ} \mathrm{C}$, as this component completely vanishes from the glow curve after such a time. This is consistent with the trap lifetimes given in Table 1. As expected, intensities of the higher-temperature TL components are hardly affected even after having the irradiated specimen for 17 days in darkness. Yet, a small decrease of the signal around $250{ }^{\circ} \mathrm{C}$ without any changes about $340{ }^{\circ} \mathrm{C}$ is seen. However, 9 months delay gives $\mathrm{TL}$ signal whose intensity comprised in both the high-temperature components is reduced by almost $30 \%$. This loss is higher than predicted by the calculated trap lifetimes given in Table 1 . Hence, even energy from the deep traps can partially leak out of them at RT within a few months though the Arrhenius dependence predicted much better stability. It is not a trivial effect and its grounds are not fully understandable at present. A possible explanation could be a slow cascade detrapping (CD). Such a mechanism was reported for TL bands with high frequency factors combined with high activation energies, ${ }^{28}$ similarly to what we observe. Yet, at this stage, it remains a presumption and not a conclusive statement. Nevertheless, the stability of the TL signal in time is very good and may make the $\mathrm{Lu}_{2} \mathrm{O}_{3}: \mathrm{Pr}$, Hf composition an interesting material for high energy particles dosimetry in some circumstances.

Figure 6a compares TL glow curves recorded using a specific procedure: first the sample was XRayed at RT then its temperature was raised to a defined value (given in Figure 6a) and immediately cooled to RT. Afterwards, a TL glow curve was recorded. This set of experiments gave an elegant, clear confirmation of the structure of traps we received from deconvolution of the glow curve given in Figure 3. First of all, it appears clear that the TL band peaking around $250{ }^{\circ} \mathrm{C}$ is composed of two components among which the higher-temperature one was nicely 
exposed by TL glow curve recorded on the material shortly preheated up to $215^{\circ} \mathrm{C}$ as well as $225^{\circ} \mathrm{C}$. Its position in Figure 6 a coincides with the component \#4 seen in Figure 3 and Table 1.

What is more, the TL curves recorded after preheating of the sample at the temperatures in the range of $245-315^{\circ} \mathrm{C}$ clearly shows that the intensity of the TL band peaking around $340{ }^{\circ} \mathrm{C}$ gets continuously reduced as the preheating temperature gets higher and that this effect is much stronger at the low-temperature side of this TL band. Such a behavior is also consistent with the findings seen in Figure 3, where the highest-temperature TL band was found to be a superposition of two strongly overlapping components, resulting from traps with similar parameters (Table 1). Experiments whose results are given in Figure $6 \mathrm{~b}$ support the above conclusions. This figure gives a set of glow curves recorded when the sample after being XRayed was additionally exposed to $980 \mathrm{~nm}, 780 \mathrm{~nm}$ or $400 \mathrm{~nm}$ radiation. The $980 \mathrm{~nm}$ stimulation (red line) removes the low temperature components (\#1-3) from the TL glow curve leaving basically unaffected the constituents \#4-6 (see also Figure 3 and Table 1). The band located around $135{ }^{\circ} \mathrm{C}$ disappears completely together with a significant portion of the main $\mathrm{TL}$ constituent around $250{ }^{\circ} \mathrm{C}$. Note, that this is the low temperature fraction of the main TL band $\left(\sim 250^{\circ} \mathrm{C}\right)$ which disappeared upon the $980 \mathrm{~nm}$ radiation. Consequently, the trap \#4 was basically unaffected. Hence, the $980 \mathrm{~nm}(\sim 1.26 \mathrm{eV})$ radiation is able to kick off the carriers from traps \#13 without touching carriers in traps \#4-6. Stimulation with $780 \mathrm{~nm}(\sim 1.6 \mathrm{eV})$ radiation bleaches, though only partially (hence: with difficulty), also the trap \#4. Clearly, such radiation carries energy which is hardly enough to reach the depth of the trap \#4. This is quite reasonable, as this trap was found to have depth of about $1.7 \mathrm{eV}$ (Table 1), which is slightly more than the $780 \mathrm{~nm}$ light carries. Yet, such conclusions should be taken with care as the mechanisms of both stimulations are so different that such elementary analogies can easily be oversimplified. Yet, 
the carriers from traps giving TL around $340{ }^{\circ} \mathrm{C}(\# 5$ and \#6) are not at all affected upon treatment with $780 \mathrm{~nm}$ radiation. This is the continuous irradiation with light of about $\sim 400 \mathrm{~nm}$ wavelength $(\sim 3 \mathrm{eV})$ which fully bleaches all the traps, as is seen in Figure $6 \mathrm{~b}$. Whichever is the stimulation, the emission comes exclusively from $\operatorname{Pr}^{3+}$ ions and appears in the red, as was presented in Figure 2. It is quiet specific situation as usually the stimulating radiation is of lower energy than the emitted one. Typically, the reading is performed by radiation whose energy is lower than luminescence caused by it.

Figure $7 \mathrm{a}$ shows changes in absorption of the ceramics induced by various irradiations, exactly the same as indicated in Figure 6b. Clearly, X-Ray irradiation suppressed the absorption in the short-UV region, where $\operatorname{Pr}^{3+} \mathrm{f}-\mathrm{d}$ bands are present. This effect is mirrored by an appearance of a broad band absorption in the $\sim 370-650 \mathrm{~nm}$ region. After subsequent stimulation with $980 \mathrm{~nm}$ and even more with $780 \mathrm{~nm}$ radiation the changes were partially reversed, especially in the long wavelength region $(\sim 450-650 \mathrm{~nm})$. However, only the treatment with $400 \mathrm{~nm}$ radiation (as well as heating up to about $350^{\circ} \mathrm{C}$, which result is not presented in Figure 7a) restored the absorption of the raw, untreated specimen. Upon such treatment both the X-Ray induced absorption band around 340-650 nm disappeared and the $\operatorname{Pr}^{3+} \mathrm{f} \rightarrow \mathrm{d}$ absorption in deep-UV regained its original intensity of the fresh ceramics.

The $340-650 \mathrm{~nm}$ absorption band seems to comprise of at least two components, as the IR photons (especially the $780 \mathrm{~nm}$ ) reduced its intensity in the long-wavelength region rather, while the absorption around 340-420 nm was barely affected. Part of the changes in absorption due to the various treatments were seen by eye - the X-Rayed specimen got rosy in color and the subsequent $400 \mathrm{~nm}$ irradiation turned it back almost white. The rosy color got deeper when the sample was X-Rayed for longer time. 
Measurements of excitation spectra of the raw and irradiated sample proved that the near-UVVis absorption induced by X-Rays is indeed a doublet. The results are presented in Figure $7 \mathrm{~b}$. After irradiation with X-Rays a new excitation band covering the $\sim 340-430 \mathrm{~nm}$ range of wavelengths is evident. It is yet much narrower than the extrinsic absorption seen in Figure 7a. This is evidence that the X-Ray induced absorption results from (at least) two different entities. In the inset of Figure $7 \mathrm{~b}$ we show how the $\operatorname{Pr}^{3+}$ luminescence decays upon continuous stimulation with $400 \mathrm{~nm}$ radiation. The emission could be easily recorded for an hour or so and its decay trace could be fitted with eq 3 using the parameter $n=0.8$. Yet, it has no physical meaning here as its value depends not only on the mechanism of the luminescence but also on the (uncontrolled, though constant during the experiment) intensity of the stimulating light. In the X-rayed specimen the excitation spectrum in the deep UV got significant enhancement. This is surprising at first, as absorption in this region (Figure 7a) was significantly reduced at the same time. Yet, such a contradictory behavior is reasonable, as through irradiation with X-Rays the traps are being filled and during the measurement of the excitation spectrum the electrons excited to the $5 \mathrm{~d}$ levels cannot escape the mother ions having no empty reservoir available. Consequently, excitation into UV gets enhancement.

The systematic changes observed in TL presented in Figure 6a,b and mirrored with the variations in absorption presented in Figure 7a allows to relate them. Thus, freeing the traps \#1-3 (980 nm) does not affect absorption below $600 \mathrm{~nm}$. Yet, even partial emptying of the trap \#4 (upon $780 \mathrm{~nm}$ stimulation) evidently reduces the extrinsic broad absorption spreading around $475 \mathrm{~nm}$ with a slight enhancement in the range of $\operatorname{Pr}^{3+} \mathrm{f} \rightarrow \mathrm{d}$ transitions at the same time. This radiation also only slightly reduces the extrinsic absorption around $370 \mathrm{~nm}$. 
Clearly, (most of) the reduced absorption of $\operatorname{Pr}^{3+}$ ion in deep UV is connected with the two deepest traps giving TL around $340{ }^{\circ} \mathrm{C}$ as only depleting them completely restores the intensity of the $\operatorname{Pr}^{3+} \mathrm{f} \rightarrow \mathrm{d}$ absorption to the level observed in the raw, untreated specimen. This is an important sign that in the doubly doped ceramics $\operatorname{Pr}^{3+}$ actively participates in energy storing, and not only in producing emission. Yet, only the deepest traps seem to be directly connected with this dopant.

The changes in absorption induced by X-Rays and the rosy body color of irradiated ceramics could be connected with the partial $\mathrm{Pr}^{3+} \rightarrow \operatorname{Pr}^{4+}$ oxidation. The $\mathrm{O}^{2-} \rightarrow \operatorname{Pr}^{4+}$ charge transfer transition indeed should be located in the near-UV or Vis part of spectrum. This would also explain the reduced absorption in the region of the $\mathrm{f} \rightarrow \mathrm{d}$ transitions of the $\operatorname{Pr}^{3+}$ (below about $330 \mathrm{~nm}$ ). Yet, the broad band in near-UV and Vis may easily result from trapped electrons in O-vacancies or at the $\mathrm{Hf}^{4+}$ codopant. We already mentioned that the broad X-Ray induced absorption comprises two components - this was evident from comparison of absorption and excitation spectra given in Figure 7a,b. Hence, it appears reasonable that two different entities give rise to the broad band appearing after exposure to X-Rays and connected with energy storing in $\mathrm{Lu}_{2} \mathrm{O}_{3}: \mathrm{Pr}, \mathrm{Hf}$.

Figure 8 presents isothermal decay traces of $\mathrm{Lu}_{2} \mathrm{O}_{3}: 0.05 \% \mathrm{Pr}, 0.1 \% \mathrm{Hf}$ ceramics obtained at seven different temperatures in the range of $150{ }^{\circ} \mathrm{C}-210{ }^{\circ} \mathrm{C}$ after irradiation with X-Rays. The experimental data were fitted with eq 3 :

$I(t)=I_{0} \times(1+\gamma t)^{-n}$,

where $\gamma=N /\left(\mathrm{a} n_{t 0}\right), N$ corresponds to the density of trapping centers, $n_{t 0}$ is the population of holes in the trapping centers at time $t=0$, and a describes the detrapping rate. ${ }^{29}$ The fitting parameter $n$ increases from around 2 to about 4 (exact numbers a given in Figure 8) when the sample temperature increases from $150{ }^{\circ} \mathrm{C}$ to $210{ }^{\circ} \mathrm{C}$. This change indicates that the retrapping 
becomes continuously less efficient with rising temperature. ${ }^{30}$ This is exactly what one may expect when temperature of the sample gets higher.

In Figure 9a TL glow curves of X-Rayed $\mathrm{Lu}_{2} \mathrm{O}_{3}: 0.05 \% \mathrm{Pr}, 0.1 \% \mathrm{Hf}$ ceramics during heating with different rates from 1 to $8{ }^{\circ} \mathrm{C} / \mathrm{s}$ are presented. No spectacular changes in the glow curves structure has been observed for different heating rates and always three main components were observed. The peak positions move towards higher temperatures with increasing heating rate, which is a typical effect. ${ }^{9,31,32}$ Figure $9 \mathrm{~b}$ shows that the variation of the peak heights for the three main bands as a function of the heating rate is insignificant, within an experiment precision. The correction for the thermal quenching (see Figure 1) was applied for these results.

\section{DISCUSSION}

The results given in Figure 1 are straightforward: efficient energy storing in $\mathrm{Lu}_{2} \mathrm{O}_{3}$ requires both Pr and $\mathrm{Hf}$ to be present in the $\mathrm{Lu}_{2} \mathrm{O}_{3}$ host. Hence, the energy storing is a co-operative effect of both dopants. Introduction of Hf has at least two important consequences. Not only do we get $\mathrm{Hf}_{\mathrm{Lu}}$ defects with positive net charge, which thus may attract electrons, but this charge has to be compensated to assure the host electrostatic neutrality. An apparent pathway of achieving it is incorporation of interstitial oxygen, $\mathrm{O}_{\mathrm{i}}^{\prime \prime}$, whose doubly negative net charge would balance two $\mathrm{Hf}_{\mathrm{Lu}}$ sites. Let us note, that incorporation of $\mathrm{O}_{\mathrm{i}}^{\prime \prime}$ would be facilitated by the lutetia host structure, as in this fluoride-type lattice two empty O-sites in the nearest coordination sphere of each metal cation are inherently present. Accordingly, we may reasonably assume that in the synthesized materials the following defect sites capable of participating in the TL process are present: $\operatorname{Pr}_{\mathrm{Lu}}^{\mathrm{X}}$, $\mathrm{Hf}_{\mathrm{Lu}}^{\circ}$, and $\mathrm{O}_{\mathrm{i}}^{\prime \prime}$ 
$\operatorname{Pr}_{\mathrm{Lu}}^{\mathrm{X}}$ is at first the emitter, hence the stored energy has to get to it somehow. Yet, it can also be an $\mathrm{h}^{\bullet}$-trapping center, as it may be capable of turning into a stable $\operatorname{Pr}^{4+}$ state, or $\left[\operatorname{Pr}^{3+}-\mathrm{h}^{\circ}\right]$ entity, similarly to $\mathrm{Tb}^{3+}$ activated persistent phosphors reported earlier ${ }^{12,33}$. Yet, as Figure 1 shows, in the Pr singly doped composition the energy is hardly stored giving rise to only inefficient TL around $340{ }^{\circ} \mathrm{C}$. This might suggest that $\operatorname{Pr}_{\mathrm{Lu}}^{\mathrm{X}}$ is not an efficient trap. However, since $\mathrm{Hf}_{\mathrm{Lu}}$ is a perfect (potential) e'-trapping center, as its positive net charge necessarily attracts the electron excited to the conduction band of the host, this process may also facilitate trapping hole in $\operatorname{Pr}_{\mathrm{Lu}}^{\mathrm{X}}$ stabilizing $\mathrm{Pr}^{4+}$ or $\left[\mathrm{Pr}^{3+}-\mathrm{h}^{\circ}\right]$ state. On the other hand, interstitial oxygen, $\mathrm{O}_{\mathrm{i}}^{\prime \prime}$, whose presence, as was discussed, is justified by the introduction of $\mathrm{Hf}$, can easily serve as an $\mathrm{h}^{\circ}$-trapping site too, due to its negative net charge. Hence, we could write the following equations to show processes through which the energy is being stored in the $\mathrm{Lu}_{2} \mathrm{O}_{3}: \operatorname{Pr}$, Hf ceramics:

$\mathrm{Hf}_{\mathrm{Lu}}^{\bullet}+\mathrm{e}^{\prime} \rightarrow \mathrm{Hf}_{\mathrm{Lu}}^{\times}$

$\mathrm{O}_{\mathrm{i}}^{\prime \prime}+\mathrm{h}^{\bullet} \rightarrow \mathrm{O}_{\mathrm{i}}^{\prime}$

$\operatorname{Pr}_{\mathrm{Lu}}^{\times}+\mathrm{h}^{\bullet} \rightarrow \operatorname{Pr}_{\mathrm{Lu}}^{\bullet}$

While the process described with eq 5 is formally possible, if hole was trapped in such a way this would leave the $\operatorname{Pr}^{3+}$ absorption after irradiation basically unaffected. Yet, the measurements proved a very significant reduction of the $\mathrm{f} \rightarrow \mathrm{d} \operatorname{Pr}^{3+}$ absorption for X-rayed sample (Figure 7a). Hence, trapping the hole at $\operatorname{Pr}^{3+}$ site appears more confident. On the other hand, one may argue that both (5) and (6) occurs. Presently, we are not in the position to definitely resolve this dilemma.

From the published data ${ }^{34}$ and the Dorenbos' model ${ }^{5}$ we calculated the position of the $\operatorname{Pr}^{3+}$ electronic levels in $\mathrm{Lu}_{2} \mathrm{O}_{3}$, whose band gap energy is about $5.6 \mathrm{eV}$ at $\mathrm{RT}^{35}$. This allowed us to develop a scheme of the electronic states of entities actively participating in the energy storing and in the TL process of $\mathrm{Lu}_{2} \mathrm{O}_{3}: \mathrm{Pr}$,Hf ceramics. This is presented in Scheme 1. The $5 \mathrm{~d}$ levels of 
$\operatorname{Pr}^{3+}$ are immersed within the conduction band, which explains why not only X-Rays but also the short UV radiation through efficient $\mathrm{f} \rightarrow \mathrm{d}$ absorption fills the traps. Simply, the electron excited to $5 \mathrm{~d}$ states of $\operatorname{Pr}^{3+}$ couples with the states of the host conduction band and thus it can escape its mother ion, diffuse for some distance to get trapped in a defect, presumably the $\operatorname{Hf}_{\mathrm{Lu}}$ site, as we already stated. Analogous trapping occurs upon irradiation with X-Rays.

The TL at the highest temperature, around $340{ }^{\circ} \mathrm{C}$ should then result from the hole trapped at $\operatorname{Pr}_{\mathrm{Lu}}^{\mathrm{X}}$ forming $\left[\operatorname{Pr}^{3+}-\mathrm{h}^{\circ}\right] / \operatorname{Pr}_{\mathrm{Lu}}^{\cdot}$ entity. Formation of $\operatorname{Pr}_{\mathrm{Lu}}^{\cdot}$ was already postulated by changes in the deep UV part of absorption spectra induced by X-Rays (Figure 7a) which indicated reduced population of $\operatorname{Pr}^{3+}$ ions after irradiation with X-Rays. Yet, contribution from the $\mathrm{O}_{\mathrm{i}}^{\prime \prime}$ to this $\mathrm{TL}$ band is not excluded.

We assign the TL around $250{ }^{\circ} \mathrm{C}$ to the energy stored in $\mathrm{Hf}_{\mathrm{Lu}}^{\circ}$. The $250^{\circ} \mathrm{C} \mathrm{TL}$ was not present even as a trace until Hf was added, see Figure 1. This band was showed to comprise two components (Figure 7). Temporarily, we think that they may reflect the presence of two metal sites, $\mathrm{C}_{2}$ and $\mathrm{C}_{3 \mathrm{i}}$, in the host material.

Now, let us deal with the low intensity TL around $135^{\circ} \mathrm{C}$. Such a TL band, but much more intense, was already reported for an efficient persistent phosphor, $\mathrm{Lu}_{2} \mathrm{O}_{3}: \mathrm{Tb}, \mathrm{Ca},{ }^{12,13}$ prepared in reducing atmosphere. Very similar situation to $\mathrm{Lu}_{2} \mathrm{O}_{3}: \mathrm{Tb}, \mathrm{Ca}$ we observe in $\mathrm{Lu}_{2} \mathrm{O}_{3}: \mathrm{Pr}$, Ca, which was not yet published. It was convincingly argued in $^{13}$ that the $135{ }^{\circ} \mathrm{C}$ TL resulted from Ovacancies abundant in $\mathrm{Lu}_{2} \mathrm{O}_{3}: \mathrm{Tb}, \mathrm{Ca}$ due to the reducing atmosphere of preparation and necessity to compensate negative net charge of $\mathrm{Ca}^{2+}$ which replaced $\mathrm{Lu}^{3+}$. In $\mathrm{Lu}_{2} \mathrm{O}_{3}: \mathrm{Pr}$, Hf the TL around $135^{\circ} \mathrm{C}$ is a minor constituent of the whole TL glow curve as in this case there are not favorable conditions to create O-vacancies. Yet, their existence as low population defects can be justified by the high temperature of preparation of the investigated ceramics. At such conditions, 
formation of Schottky defects is unavoidable and thus presence of some O-vacancies is validated. Summarizing, the TL of $\mathrm{Lu}_{2} \mathrm{O}_{3}: \mathrm{Pr}$, Hf ceramics above $200{ }^{\circ} \mathrm{C}$ is due to the $\mathrm{Pr}$ and $\mathrm{Hf}$ co-doping, while the one below $200{ }^{\circ} \mathrm{C}$ is a consequence of formation of vacant oxygen sites due to the high temperature of the ceramics' preparation. In fact the TL below $200{ }^{\circ} \mathrm{C}$, responsible for some small RT afterglow, is a drawback of the $\mathrm{Lu}_{2} \mathrm{O}_{3}: \operatorname{Pr}$,Hf storage phosphor. Yet, till now we were not able to get rid of it by means of technological tricks.

All the high temperature components of the TL glow curve $\left(>200^{\circ} \mathrm{C}\right)$ were found to have the frequency factors exceeding the Debye frequency $\left(\sim 10^{13} \mathrm{~s}^{-1}\right)$ by 3-4 orders of magnitude, see Table 1. Such high rates suggests that the mechanism of the thermally stimulated luminescence has mixed character and it is probable that the carriers get to the emitting ion not only by being excited to the conduction/valence band but also, simultaneously, by means of another channel. On the other hand, since the TL glow curve has several overlapping glow peaks the parameters derived from fitting may be burden with significant inaccuracy. As noted by Bos $^{27}$ the simple model describing the kinetics of the TL phenomenon fails in the case of overlapping TL components. Consequently, deconvolution of complex TL glow curves gives trap parameters whose values and physical meaning are doubtful. And we should keep it in mind concluding on TL properties of $\mathrm{Lu}_{2} \mathrm{O}_{3}: \mathrm{Pr}, \mathrm{Hf}$ ceramics.

The $\mathrm{Hf}_{\mathrm{Lu}}^{\circ}$ and $\mathrm{O}_{\mathrm{i}}^{\prime \prime}$ defects, owing to their net charges, can be expected to cluster forming spatially linked energy trapping complex sites. Since $\mathrm{Hf}^{4+}$ is smaller and $\mathrm{Pr}^{3+}$ is larger than $\mathrm{Lu}^{3+}$, we may further expect that even $\operatorname{Pr}_{\mathrm{Lu}}^{\mathrm{X}}$ may tend to aggregate with $\mathrm{Hf}_{\mathrm{Lu}}^{\circ}$ and $\mathrm{O}_{\mathrm{i}}^{\prime \prime}$ defects. This reasoning gets important support from the fact that high-temperature preparation significantly enhances TL efficiency (detailed results how fabrication temperature affects the TL properties were not presented in this paper). 
It was indicated $\mathrm{in}^{28}$ that the temptation to treat the traps uniformly distributed within the host is often unjustified. Traps (defects) may be forced to cluster as this may be thermodynamically advantageous. From what was said above we have good reasons to postulate that such an effect plays an important role in $\mathrm{Lu}_{2} \mathrm{O}_{3}: \operatorname{Pr}$,Hf storage phosphor and point defects form the $\left[\mathrm{Hf}_{\mathrm{Lu}^{-}}-\operatorname{Pr}_{\mathrm{Lu}^{-}}^{\mathrm{X}}\right.$ $\mathrm{O}_{\mathrm{i}}$ ] spatially correlated structures. And only then, when the distance between the various taps is reduced can efficient TL be generated.

Furthermore, the spatial correlation could also be blamed for the observed energy sink from the deep traps (Figure 5) seen after a few months, while from the traps parameters their stability should be higher (Table 1). We claim that this is the spatial correlation of the point defects which allows for their communication and energy exchange leading to the observed fading. Note that the ${ }^{1} \mathrm{D}_{2}$ emitting level of $\operatorname{Pr}^{3+}$ and the $\mathrm{Hf}_{\mathrm{Lu}}$ trap state energetically coincide (Scheme 1), which such energy diffusion may make only more probable. Thus all the results can be logically combined into a consistent picture explaining the properties of the $\mathrm{Lu}_{2} \mathrm{O}_{3}: \mathrm{Pr}$, Hf storage phosphor ceramics.

\section{CONCLUSIONS}

In this paper we report on spectroscopic properties of the $\mathrm{Lu}_{2} \mathrm{O}_{3}: \mathrm{Pr}$, Hf sintered ceramic storage phosphors and discuss the mechanisms standing behind the observed processes. The whole variety of experimental data collected measuring thermoluminescence, optically stimulated luminescence, fading, isothermal decay traces, photoluminescence and excitation spectra, luminescence decay times as well as data from analytical deconvolution of the glow curves gave consistent picture as to the physics standing behind the thermoluminescence. The glow curve deconvolution gave as much as six, partly overlapping components forming three bands peaking 
around $130{ }^{\circ} \mathrm{C}, 250{ }^{\circ} \mathrm{C}$ and $340{ }^{\circ} \mathrm{C}$. It was found that the last two, being the main TL constituents, result from $\mathrm{Hf}(\mathrm{IV})$ replacing $\mathrm{Lu}(\mathrm{III})$ in the host $\left(250{ }^{\circ} \mathrm{C}\right)$ and the $\mathrm{Pr}^{3+}$ activator itself, maybe with some contribution from interstitial oxygen $\left(340^{\circ} \mathrm{C}\right)$. Trap depths were found to cover the $0.8-2.1 \mathrm{eV}$ range of energies. The TL process was found to follow the first-order kinetics. It was showed that bleaching of the traps giving rise to the TL at lower temperatures (traps \#1-3) is possible without affecting the energy stored in the other traps. Furthermore, energy from the trap \#4 could also be freed without loss of carriers entrapped in traps \#5 and \#6. This could be attained either by controlled thermal stimulation or with infrared photons whose energy was properly tuned. The stored energy could be freed totally by heating the materials up to about $450{ }^{\circ} \mathrm{C}$ or with $\sim 400 \mathrm{~nm}$ radiation. Changes observed in absorption and excitation spectra were harmonized with the variations in the course of the glow curve and altogether a consistent picture the observed spectroscopic processes was obtained. Agglomeration of defects due to the high temperature fabrication process was postulated to be beneficial for TL efficacy, e.g. for the amount of energy possible to freeze in the $\mathrm{Lu}_{2} \mathrm{O}_{3}: \mathrm{Pr}, \mathrm{Hf}$ ceramics. Fading was found to reach only about $30 \%$ within the first nine months. Such a good long term stability of the thermoluminescence signal and high efficiency of absorption of ionizing radiation of the lutetia host may make the $\mathrm{Lu}_{2} \mathrm{O}_{3}: \mathrm{Pr}$,Hf composition an interesting material for high energy gamma particles dosimetry. 


\section{FIGURES}

Figure 1. TL glow curves of undoped $\mathrm{Lu}_{2} \mathrm{O}_{3}$, singly doped $\mathrm{Lu}_{2} \mathrm{O}_{3}: 0.05 \% \mathrm{Pr}$, and $\mathrm{Lu}_{2} \mathrm{O}_{3}: 0.1 \% \mathrm{Hf}$ and doubly doped $\mathrm{Lu}_{2} \mathrm{O}_{3}: 0.05 \% \mathrm{Pr}, 0.1 \% \mathrm{Hf}$ ceramics measured immediately after irradiation with X-Rays. The blue curve with dots gives a temperature dependence of the decay time of $\operatorname{Pr}^{3+}$ luminescence.

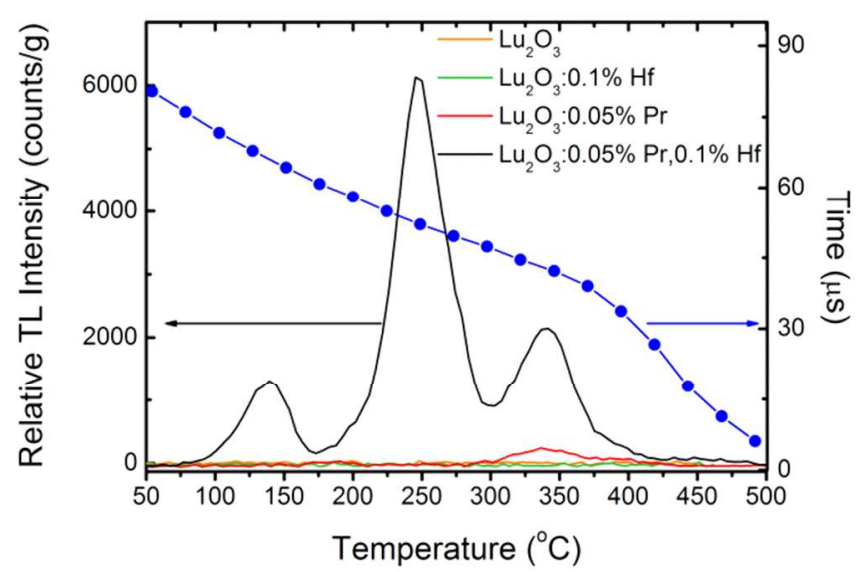

Figure 2. Room temperature excitation spectra of $610 \mathrm{~nm}$ and $631.5 \mathrm{~nm}$ emissions (left), photoluminescence spectrum under $275 \mathrm{~nm}$ excitation and thermoluminescent emission spectrum of $\mathrm{Lu}_{2} \mathrm{O}_{3}: 0.05 \% \mathrm{Pr}, 0.1 \% \mathrm{Hf}$ ceramics recorded at $250{ }^{\circ} \mathrm{C}$ (right).

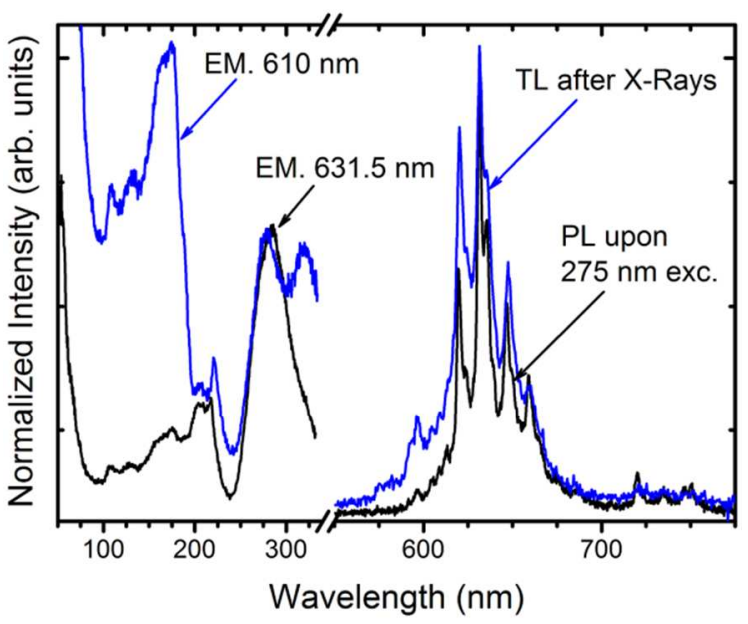


Figure 3. TL glow curve of $\mathrm{Lu}_{2} \mathrm{O}_{3}: 0.05 \% \mathrm{Pr}, 0.1 \% \mathrm{Hf}$ ceramics recorded after irradiation with $\mathrm{X}$ Rays for 5 minutes (solid line). Deconvolution of the experimental curve using the first-order kinetics gave six components presented with dotted lines. Constituent \#2 has negligible intensity. See also Table 1.

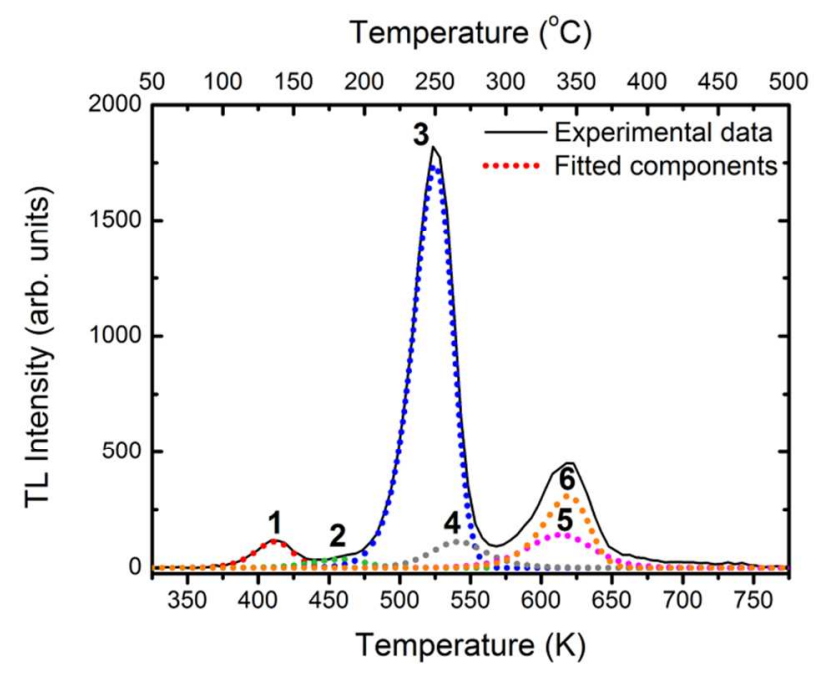

Figure 4. Influence of irradiation time with X-Rays on the thermoluminescence glow curves of $\mathrm{Lu}_{2} \mathrm{O}_{3}: 0.05 \% \mathrm{Pr}, 0.1 \% \mathrm{Hf}$ ceramics (a), and integrated TL intensities of the three bands (b). The solid lines introduced just to guide the eye.
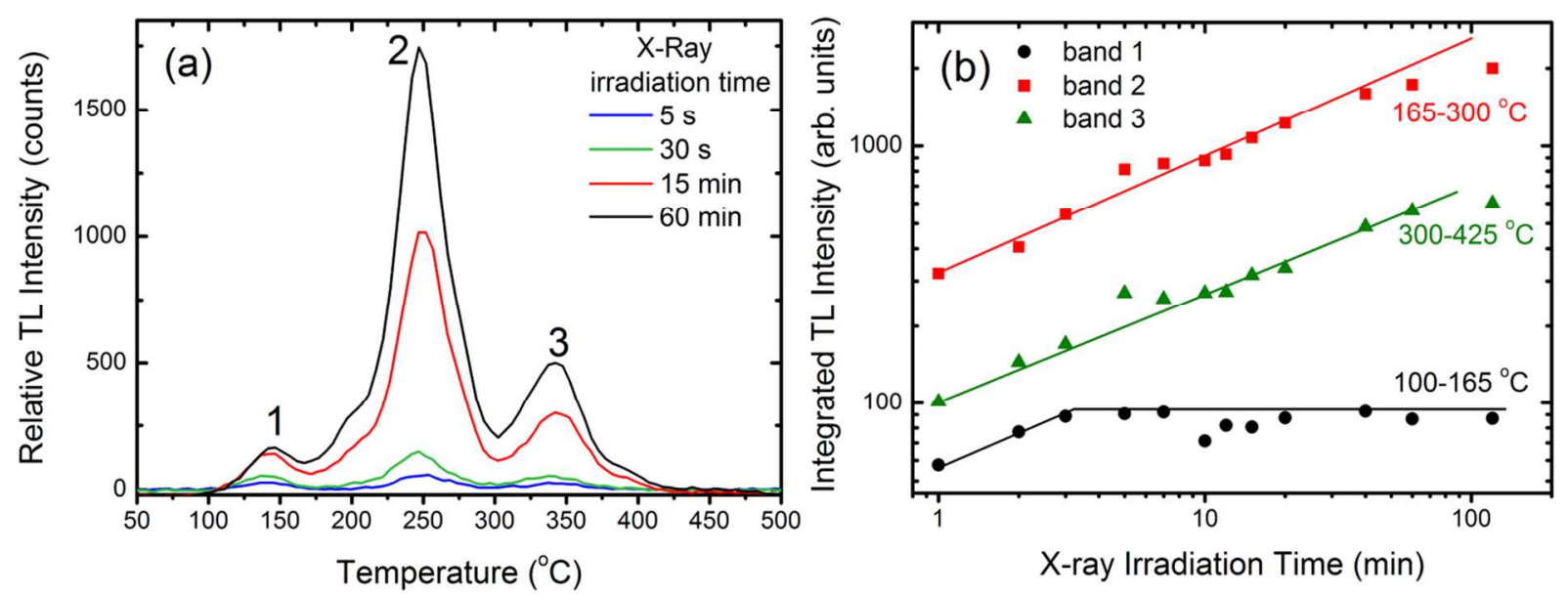
Figure 5. TL glow curves of the $\mathrm{Lu}_{2} \mathrm{O}_{3}: 0.05 \% \mathrm{Pr}, 0.1 \% \mathrm{Hf}$ ceramics measured following different delay time (indicated in the figure) after its exposure into $254 \mathrm{~nm}$ UV radiation for 15 minutes. The sample was kept at RT all the time.

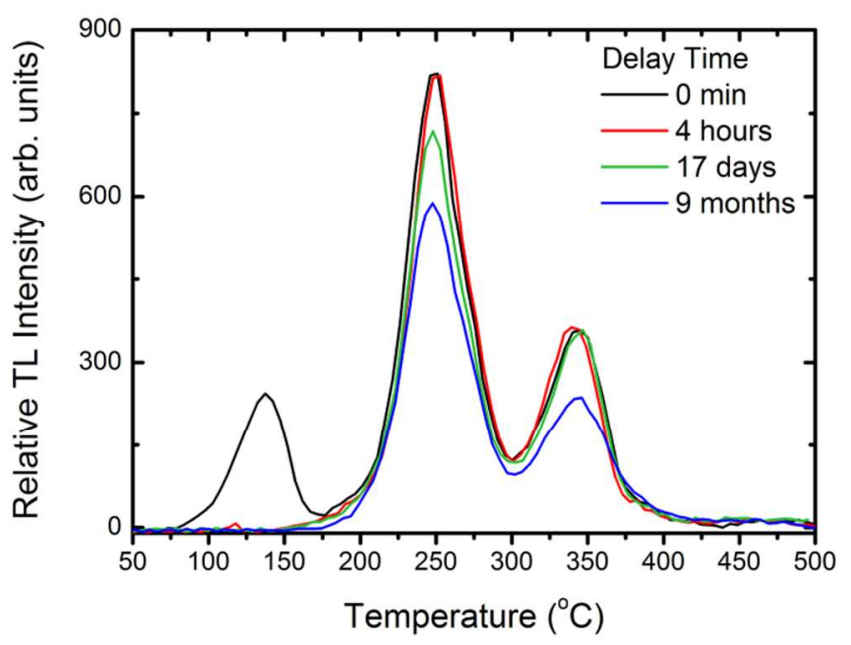

Figure 6. TL glow curves of $\mathrm{Lu}_{2} \mathrm{O}_{3}: 0.05 \% \mathrm{Pr}, 0.1 \% \mathrm{Hf}$ ceramics measured shortly after X-Ray irradiation and after subsequent preheating to different temperatures from $160{ }^{\circ} \mathrm{C}$ to $315^{\circ} \mathrm{C}$ (a). TL glow curves measured shortly after X-Ray irradiation and after subsequent stimulation with $980 \mathrm{~nm}, 780 \mathrm{~nm}, 400 \mathrm{~nm}$ diode lasers for 30 minutes (b).
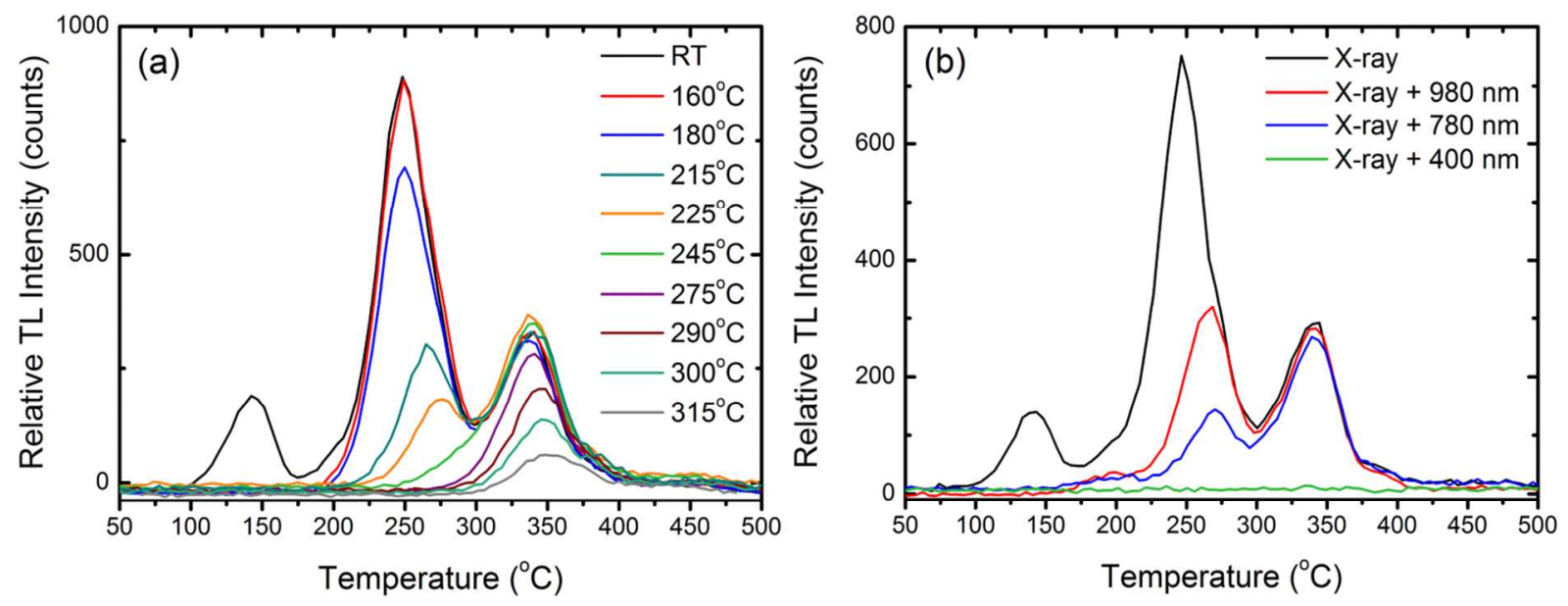
Figure 7. Absorption spectra of $\mathrm{Lu}_{2} \mathrm{O}_{3}: 0.05 \% \mathrm{Pr}, 0.1 \% \mathrm{Hf}$ raw ceramics and after $\mathrm{X}-\mathrm{Ray}$ irradiation and additional stimulation with $980 \mathrm{~nm}, 780 \mathrm{~nm}, 400 \mathrm{~nm}$ diode lasers for 30 minutes (a). Excitation spectra of $632 \mathrm{~nm}$ emission of raw sample and after X-Ray irradiation followed by additional $400 \mathrm{~nm}$ stimulation for 15 minutes (b). Insert in (b): Logarithmic dependence of luminescence intensity vs. time recorded during $400 \mathrm{~nm}$ continuous stimulation following the XRay irradiation.
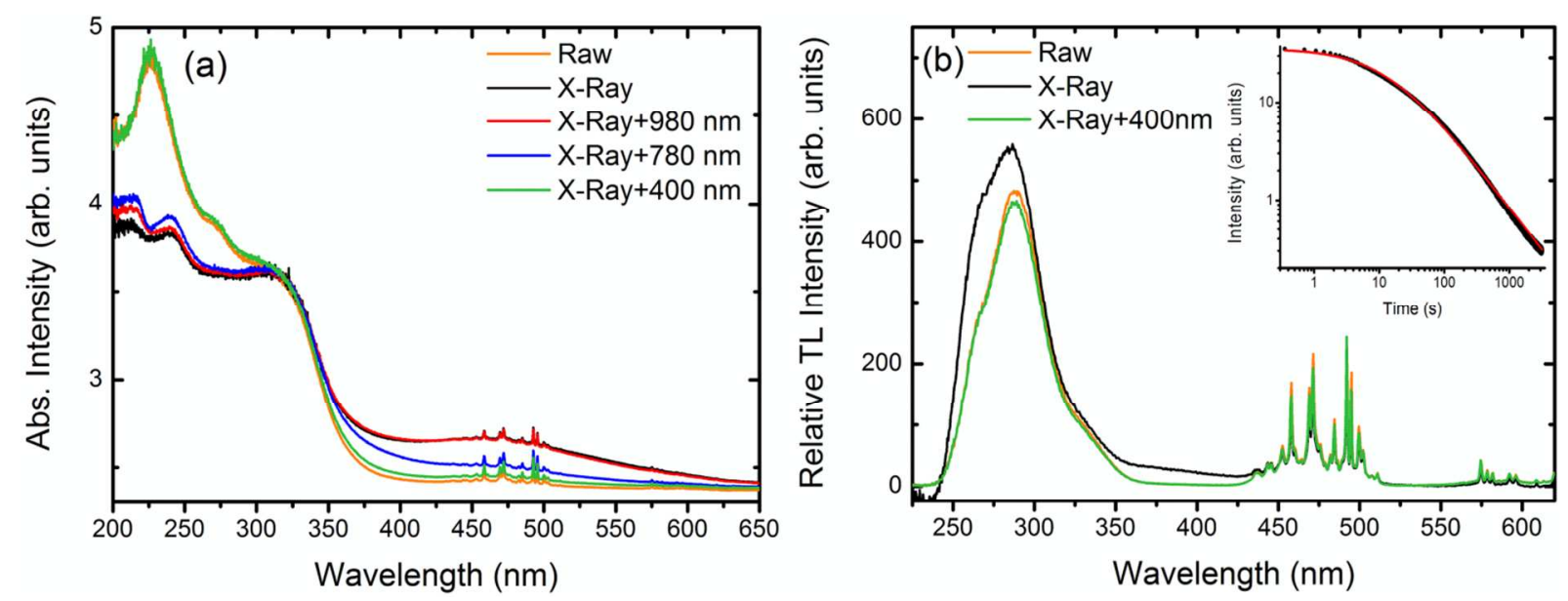
Figure 8. The isothermal phosphorescence decay traces of $\mathrm{Lu}_{2} \mathrm{O}_{3}: 0.05 \% \mathrm{Pr}, 0.1 \% \mathrm{Hf}$ ceramics recorded at seven different temperatures from $150{ }^{\circ} \mathrm{C}$ to $210{ }^{\circ} \mathrm{C}$ after 5 minutes X-Ray irradiation. Solid lines results from fits with eq 3.

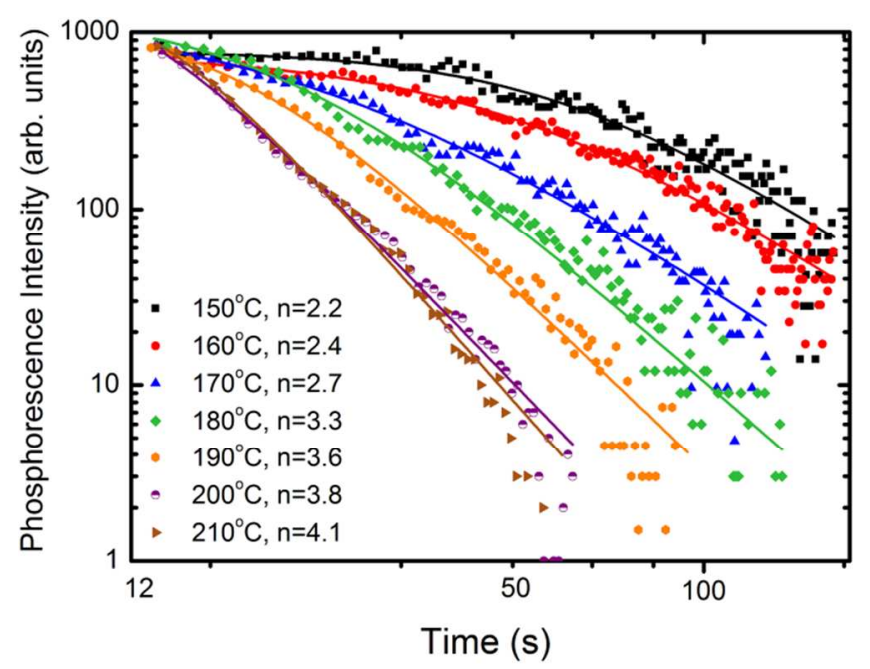

Figure 9. Normalized to the same height TL glow curves of $\mathrm{Lu}_{2} \mathrm{O}_{3}: 0.05 \% \mathrm{Pr}, 0.1 \% \mathrm{Hf}$ ceramics measured with different heating rate of $1,2,5,8^{\circ} \mathrm{C} / \mathrm{s}$ after irradiation with X-Rays (a). Variation of the intensities (height/ $\beta$ ) of the three main bands of glow curves as a function of the heating rate (b).
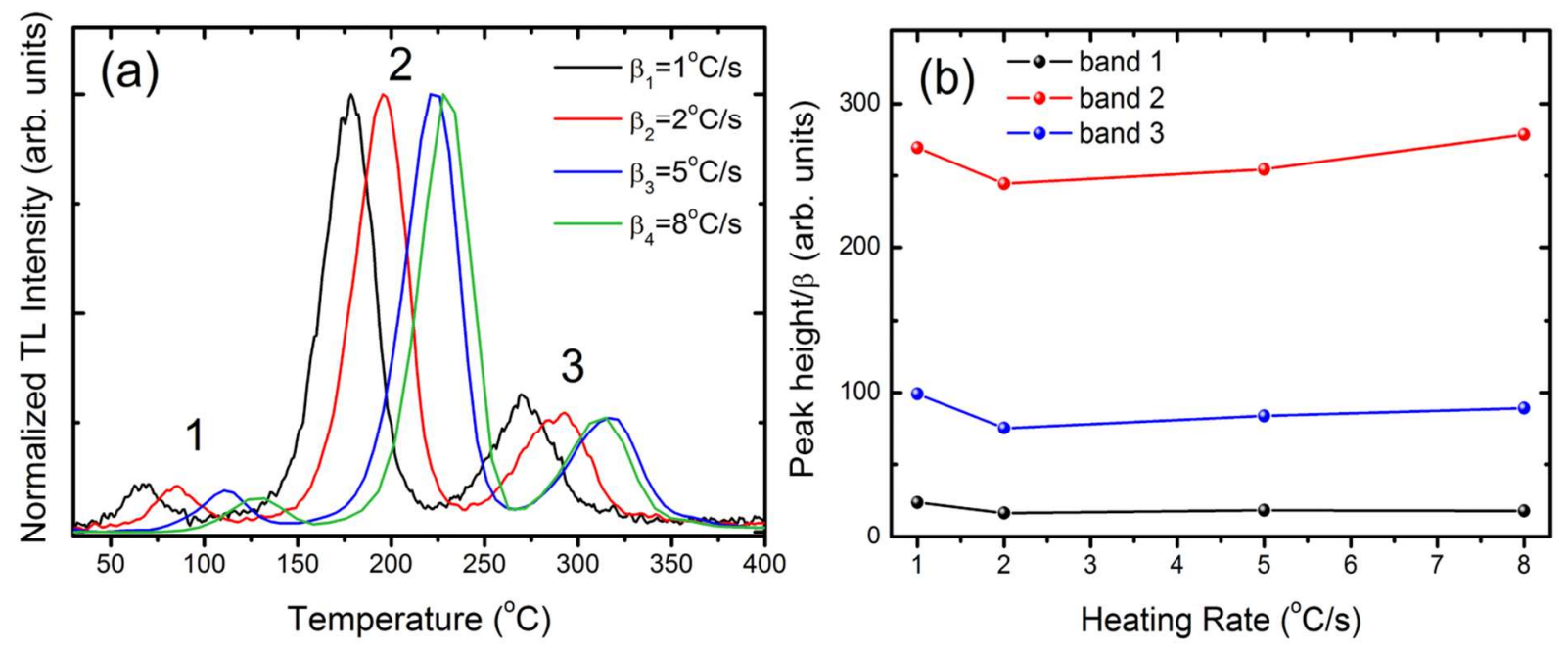


\section{SCHEMES}

Scheme 1. Scheme of the electronic states involved into the energy storing and connected with $\operatorname{Pr}^{\mathrm{X}}{ }_{\mathrm{Lu}} / \mathrm{O}_{\mathrm{i}}{ }^{\prime \prime}, \mathrm{Hf}_{\mathrm{Lu}}^{\bullet}, V_{\mathrm{O}}^{\bullet}$ defects, related to the $\operatorname{Pr}^{3+}$ levels and the host band structure.

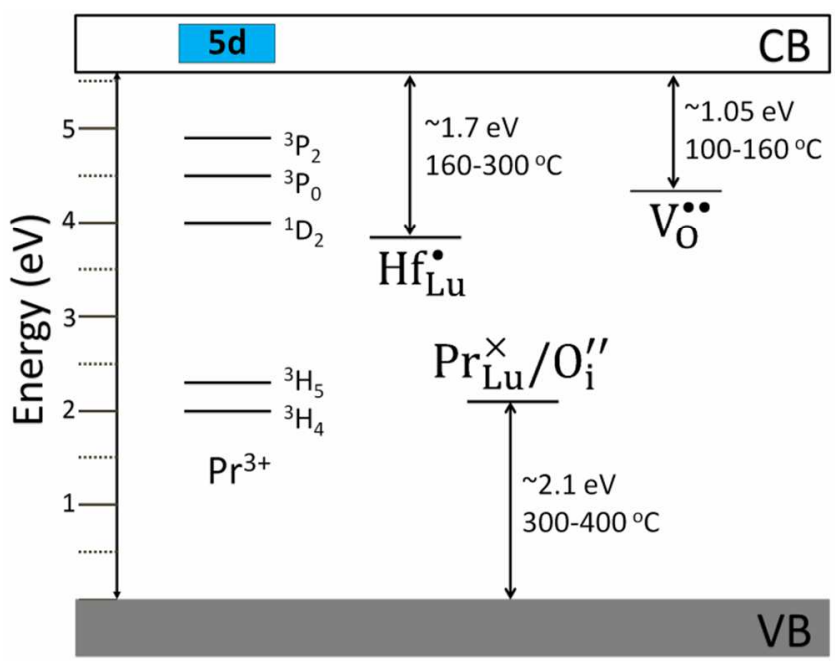

\section{TABLES}

Table 1. Table 1. Parameters of the traps derived by the deconvolution of the measured TL glow curve of $\mathrm{Lu}_{2} \mathrm{O}_{3}: 0.05 \% \mathrm{Pr}, 0.1 \% \mathrm{Hf}$ ceramics obtained using first-order kinetics approach.

\begin{tabular}{|l|l|l|l|l|}
\hline Trap No. & $T\left({ }^{\circ} \mathrm{C}\right)$ & $E(\mathrm{eV})$ & $s\left(\mathrm{~s}^{-1}\right)$ & $\tau(\mathrm{h})$ \\
\hline 1 & 137 & 1.14 & $1 \times 10^{14}$ & 113 \\
\hline
\end{tabular}




\begin{tabular}{|l|l|l|l|l|}
\hline 2 & 181 & 0.83 & $3 \times 10^{9}$ & 17.5 \\
\hline 3 & 250 & 1.69 & $4 \times 10^{16}$ & $8.2 \times 10^{8}$ \\
\hline 4 & 270 & 1.71 & $2 \times 10^{16}$ & $3.6 \times 10^{9}$ \\
\hline 5 & 335 & 2.11 & $3 \times 10^{17}$ & $1.8 \times 10^{15}$ \\
\hline 6 & & & & \\
\hline
\end{tabular}

\section{Displayed equations}

$$
\begin{aligned}
& I(t)=-\frac{d n}{d t}=s n \exp \left(-\frac{E}{k T}\right), \\
& \tau=s^{-1} \exp \left(\frac{E}{k T}\right) \\
& I(t)=I_{0} \times(1+\gamma t)^{-n}, \\
& \mathrm{Hf}_{\mathrm{Lu}}^{\bullet}+\mathrm{e}^{\prime} \rightarrow \mathrm{Hf}_{\mathrm{Lu}}^{\times} \\
& \mathrm{O}_{\mathrm{i}}^{\prime \prime}+\mathrm{h}^{\bullet} \rightarrow \mathrm{O}_{\mathrm{i}}^{\prime} \\
& \operatorname{Pr}_{\mathrm{Lu}}^{\times}+\mathrm{h}^{\bullet} \rightarrow \operatorname{Pr}_{\mathrm{Lu}}^{\bullet}
\end{aligned}
$$

\section{AUTHOR INFORMATION}




\author{
Corresponding Author \\ *eugeniusz.zych@chem.uni.wroc.pl \\ Tel. +48713757248 \\ Fax. +48713282348
}

\title{
Funding Sources
}

The research was supported by Wroclaw Research Centre EIT+ within the project "The Application of Nanotechnology in Advanced Materials" - NanoMat (POIG.01.01.02-02-002/08)

financed by the European Regional Development Fund (Innovative Economy Operational Program 1.1.2). We also acknowledge partial support by DESY Hasylab Grant \# II-20090289 EC.

\section{ACKNOWLEDGMENT}

The authors are indebted to Professor Arkadiusz Mandowski from Jan Dlugosz Academy in Czestochowa, Poland for stimulating discussions and suggestions.

\section{REFERENCES}

[1] McKeever, S. W. S. Thermoluminescence of Solids, Cambridge University Press, Cambridge, U.K., 1985.

[2] Chen, R.; McKeever, S. W. S. Theory of Thermoluminescence and Related Phenomena, World Scientific, Singapore, 1997. 
[3] Furreta, C. Handbook of Thermoluminescence, World Scientific, Singapore, 2003.

[4] Hölsä, J.; Laamanen, T.; Lastusaari, M.; Malkamäki, M.; Novák, P. J. Lumin. 2009, 129, 1606.

[5] Dorenbos, P.; Bos, A. J. J. Radiat. Meas. 2008, 43, 139.

[6] Bos, A. J. J.; Dorenbos, P.; Bessière, A.; Viana, B. Radiat. Meas. 2008, 43, 222.

[7] Lecointre, A.; Bessière, A.; Bos, A. J. J.; Dorenbos, P.; Viana, B.; Jacquart, S. J. Phys. Chem. C 2011, 115, 4217.

[8] Dorenbos, P.; Bos, A. J. J.; Poolton, N. R. J. Opt. Mater. 2011, 33, 1019.

[9] Bos, A. J. J.; Dorenbos, P.; Bessière, A.; Lecointre, A.; Bedu, M.; Bettinelli, M.; Piccinelli, F. Radiat. Meas. 2011 doi:10.1016/j.radmeas.2011.04.021.

[10] Leverenz, H.W. An Introduction to Luminescence of Solids, John Wiley and Sons, New York, USA, 1950.

[11] Daunay, J.; Daunay J.; Batailler, G. J. Lumin. 1973, 6, 44.

[12] Trojan-Piegza, J.; Niittykoski, J.; Hölsä, J.; Zych, E. Chem. Mater. 2008, 20, 2252.

[13] Trojan-Piegza, J.; Zych, E.; Hölsä, J.; Niittykoski, J. J. Phys. Chem. C 2009, 113, 20493.

[14] Kulesza, D.; Trojan-Piegza, J.; Zych, E. Radiat. Meas. 2010, 45, 490.

[15] Kulesza, D.; Wiatrowska, A.; Trojan-Piegza, J.; Felbeck, T.; Geduhn, R.; Motzek, P.; Zych, E.; Kynast, U. J. Lumin. 2013, 133, 51. 
[16] Zych, E.; Wiatrowska, A. Luminescent material as well as a method of obtaining it, PTC/PL2012/050002.

[17] Pechini, M. P. Method of preparing lead and alkaline earth titanates and niobates and coating method using the same to form a capacitor, U. S. Patent 3,330,697, 1967.

[18] Puchalska, M.; Bilski, P. Radiat. Meas. 2006, 41, 659.

[19] Kröger, F. A.; Vink. H. H. In Solid State Phys.; Seitz, F; Turnbull, D. Eds.; Academic Press: San Diego, CA 1956; Vol. 3, p 273.

[20] http://old.iupac.org/publications/books/rbook/Red_Book_2005.pdf.

[21] FindIt Database (ICSD\#40471).

[22] Trojan-Piegza, J.; Zych, E. J. Alloy. Compd. 2004, 380, 118.

[23] Wang, Z.; Zhang, W.; Lin, L.; You, B.; Fu, Y.; Yin, M. Opt. Mater. 2008, 30, 1484.

[24] Galceran, M.; Pujol, M.C.; Aguiló, M.; Díaz, F. Mater. Sci. Eng. B 2008, 146, 7.

[25] De Mello Donegá, C.; Meijerink, A.; Blasse, G.; J. Phys. Chem. Solids 1995, 56, 673.

[26] Zych, E.; Wawrzyniak, M.; Kossek, A.; Trojan-Piegza, J.; Kępiński, L. J. Alloy. Compd. 2008, 451, 591.

[27] Bos, A. J. J. Radiat. Meas. 2007, 41, S45.

[28] Mandowski, A. Radiat. Prot. Dosim. 2006, 119(1-4), 23. 
[29] Nakazava, E. In Phosphor Handbook; Shionoya, S.; Yen, W. M. Eds.; CRC Press, Boca

Raton, 1999, p 85.

[30] Jia, D.; Zhu, J.; Wu, B. J. Lumin. 2000, 91, 59.

[31] Anishia, S. R.; Jose, M. T.; Annalakshmi, O.; Ramasamy, V. J. Lumin. 2011, 131, 2492.

[32] Krumpel, A. H.; Van der Kolk, E.; Zeelenberg, D.; Bos, A. J. J.; Krämer, K. W.; Dorenbos, P. J. Appl. Phys. 2008, 104, 073505.

[33] Hosono, H.; Kinoshita, T.; Kawazoe, H.; Yamazaki, M.; Yamamoto, Y.; Sawanobori, N. J. Phys.: Condens. Matter 1998, 10, 9541.

[34] Yen, W. J. Lumin. 1999, 83-84, 399.

[35] Prokofiev, A. V.; Shelykh, A. I.; Melekh, B. T. J. Alloy. Compd. 1996, 242, 41. 


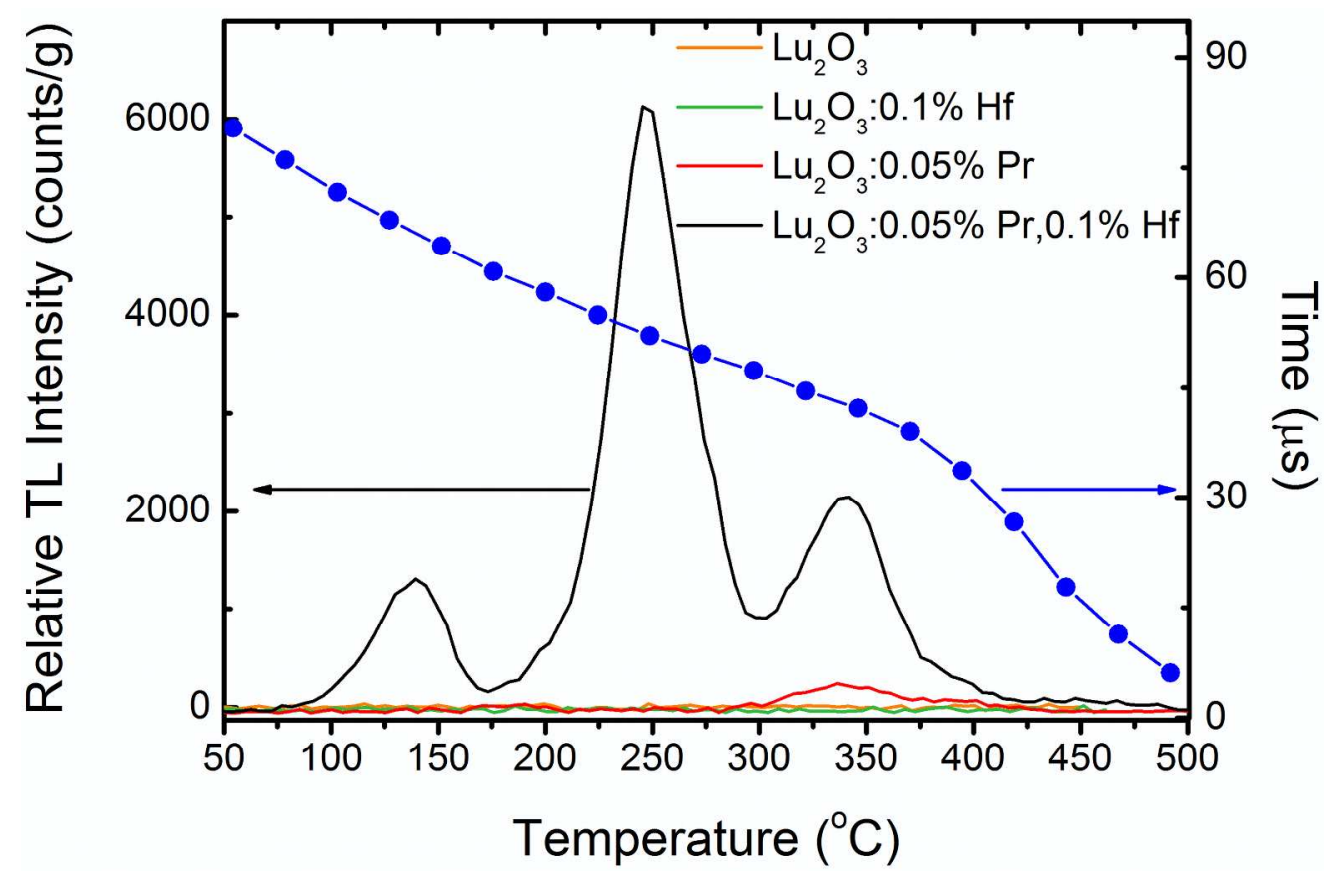

$1069 \times 708 \mathrm{~mm}(72 \times 72$ DPI $)$ 


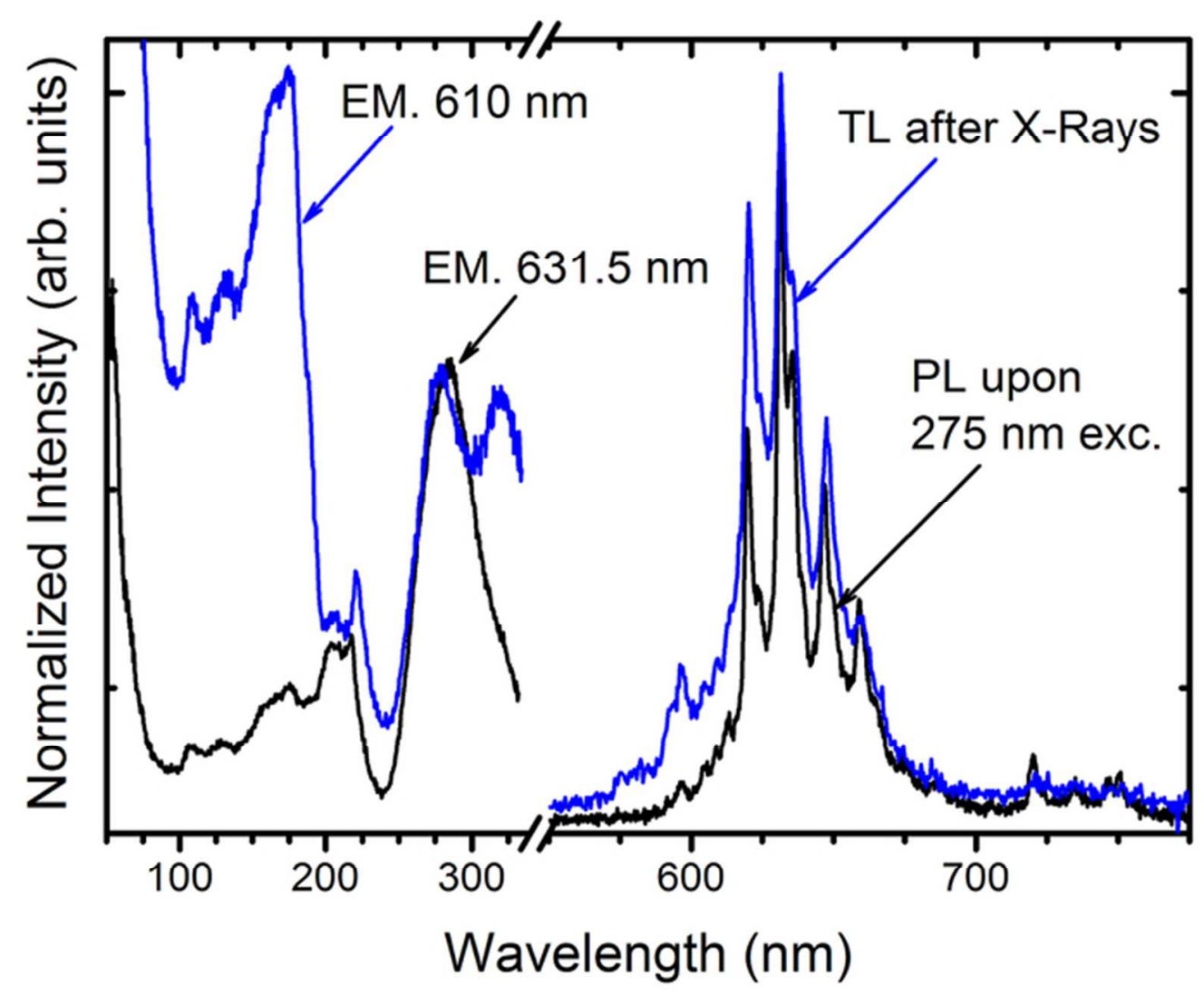

$57 \times 47 \mathrm{~mm}(300 \times 300$ DPI $)$ 


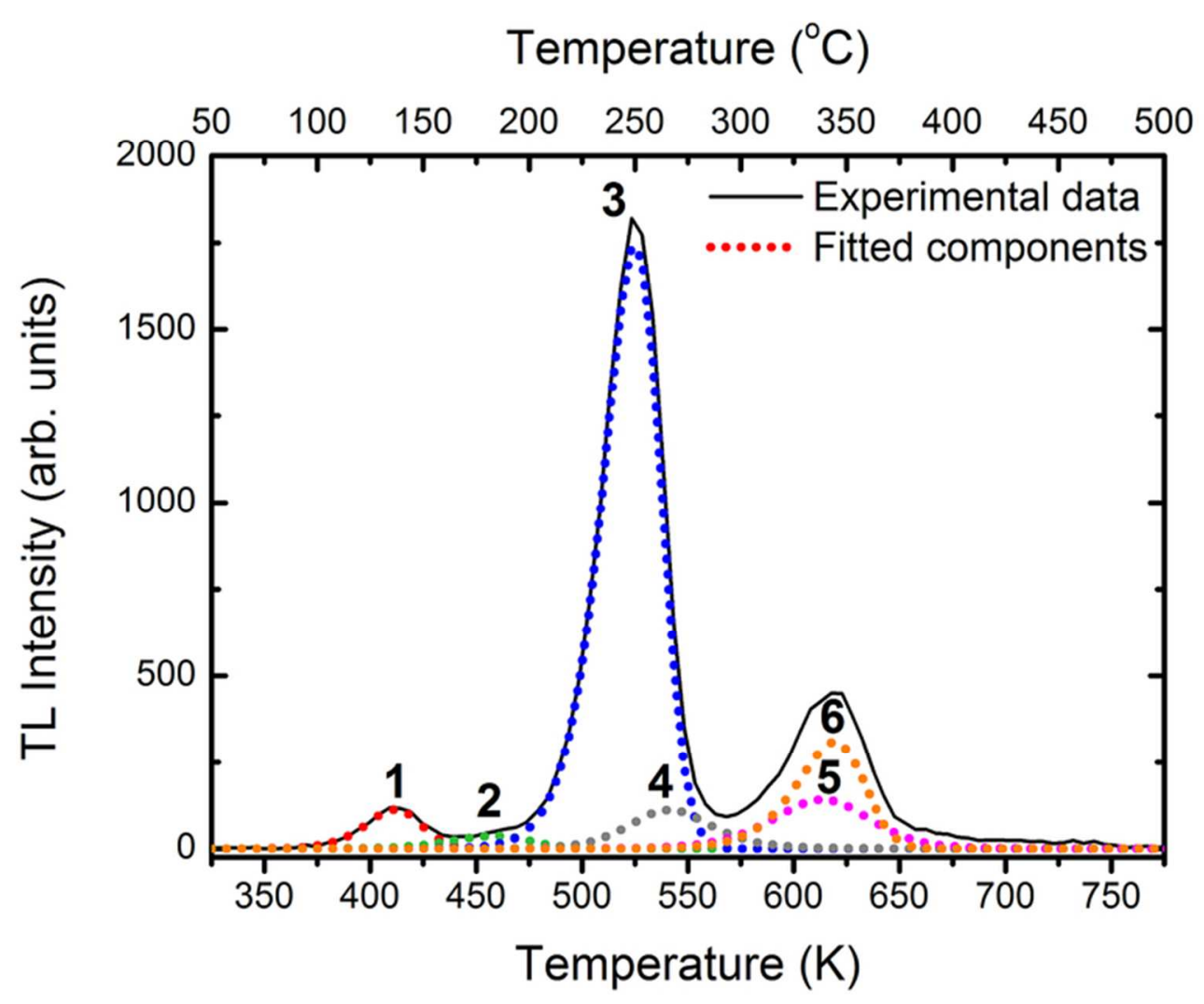

$66 \times 52 \mathrm{~mm}(300 \times 300$ DPI $)$ 

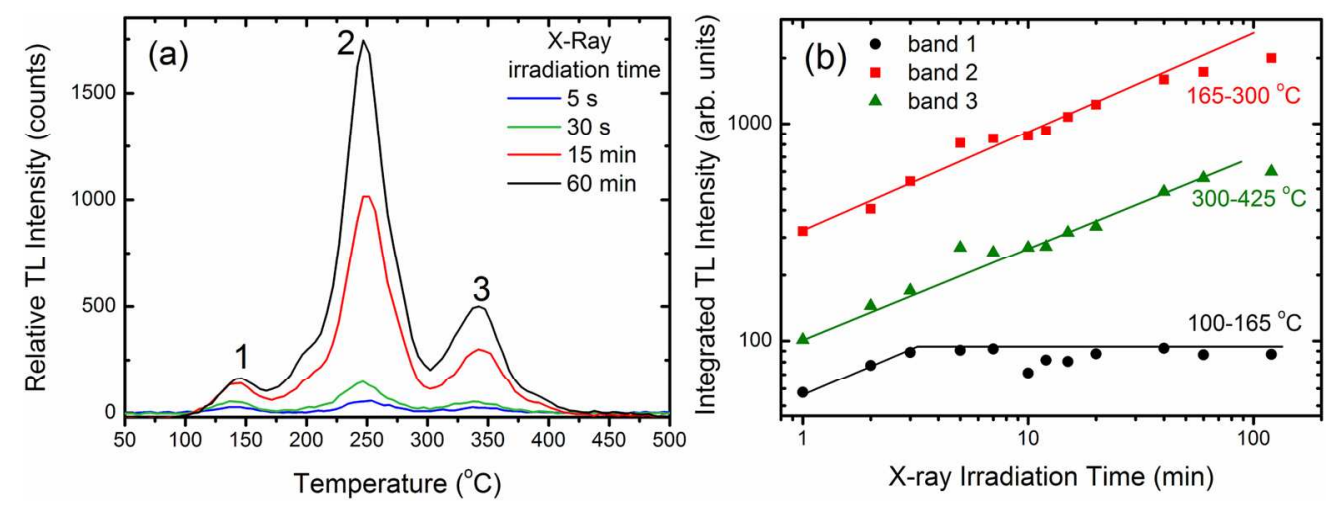

$160 \times 60 \mathrm{~mm}(300 \times 300 \mathrm{DPI})$ 


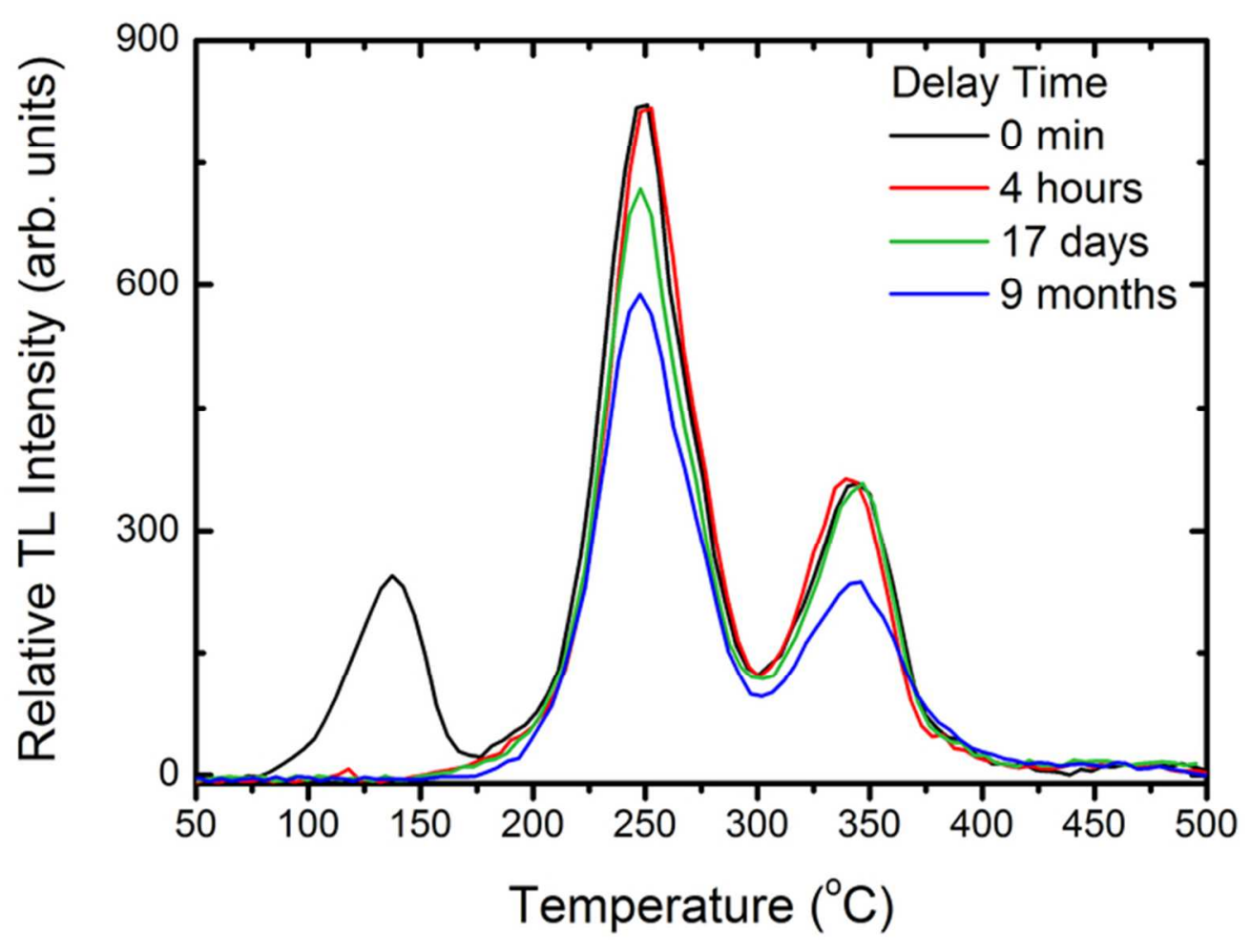

$61 \times 45 \mathrm{~mm}(300 \times 300 \mathrm{DPI})$ 

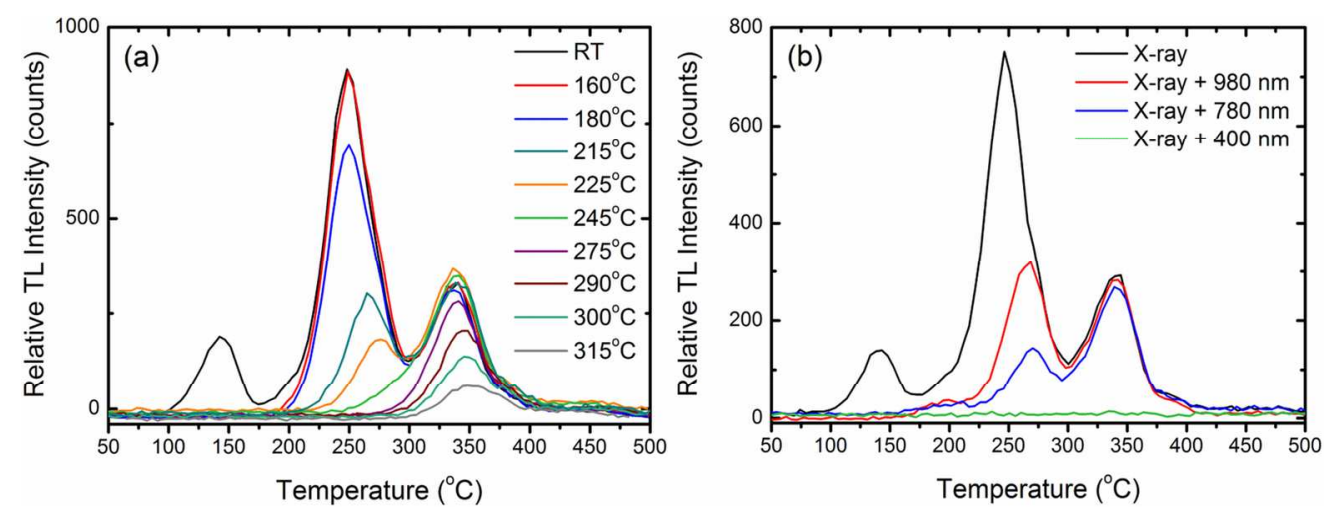

$160 \times 60 \mathrm{~mm}(300 \times 300 \mathrm{DPI})$ 


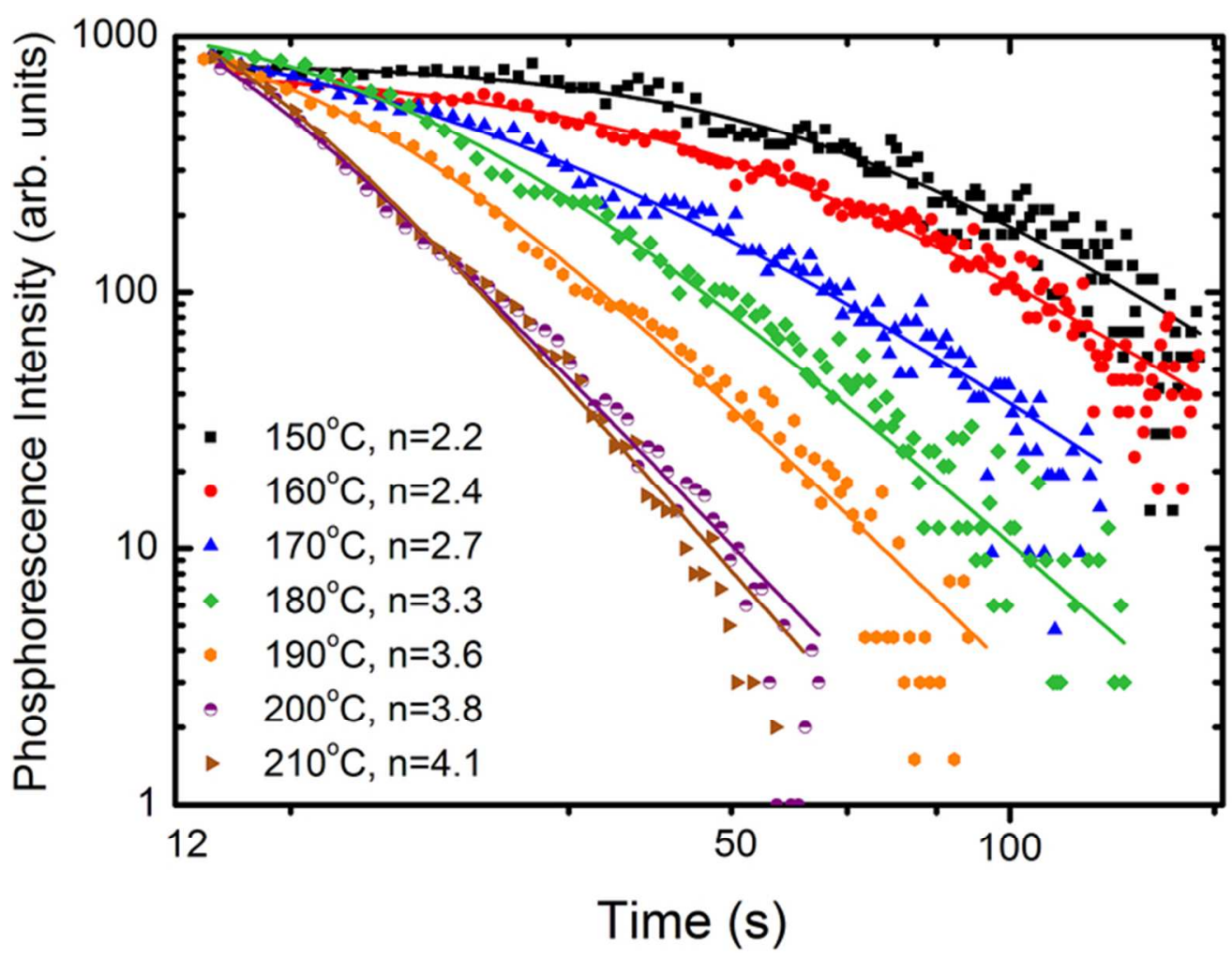

$63 \times 48 \mathrm{~mm}(300 \times 300$ DPI $)$ 

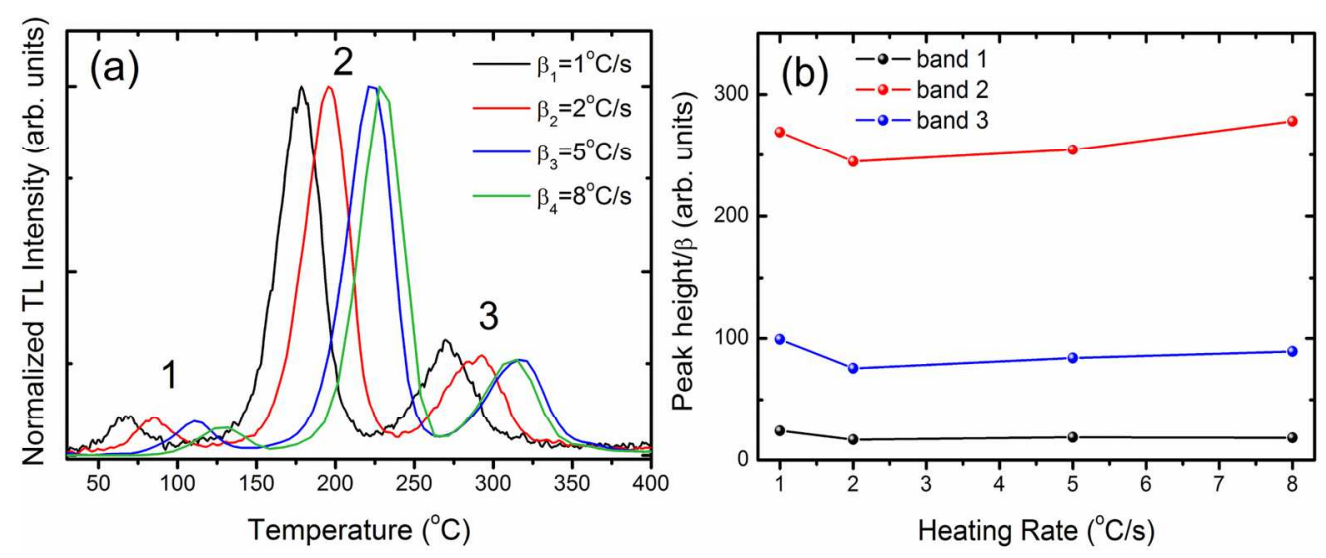

$160 \times 65 \mathrm{~mm}(300 \times 300$ DPI $)$ 


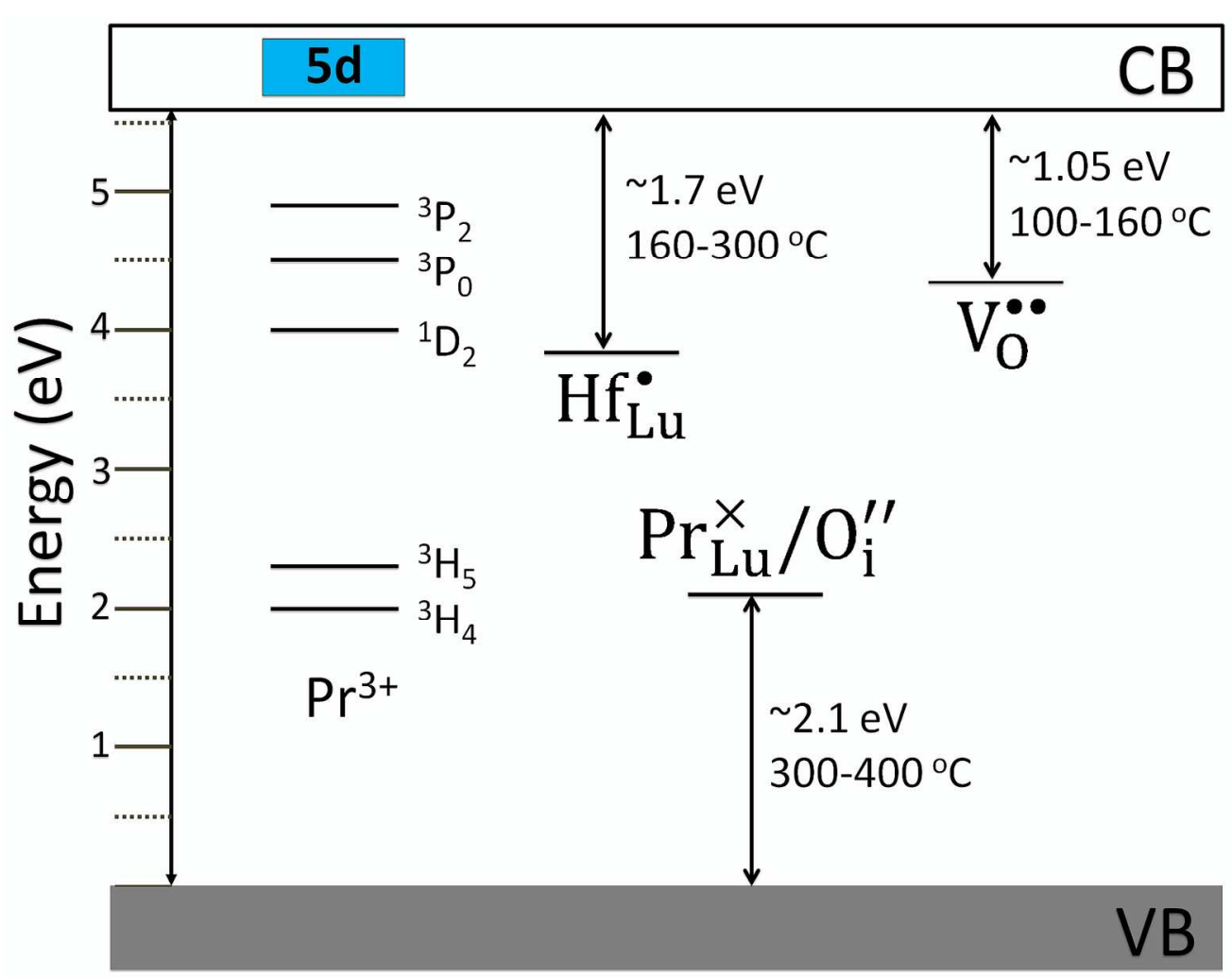

$687 \times 539 \mathrm{~mm}(72 \times 72$ DPI $)$ 


1
1
3
4
5
6
7
8
9
10
11
12
13
14
15
16
17
18
19
20
21
22
23
24
25
26
27
28
29
30
31
32
33
34
35
36
37
38
39
40
41
42
43
44
55
50
56
57
48
59
50
51
53
50

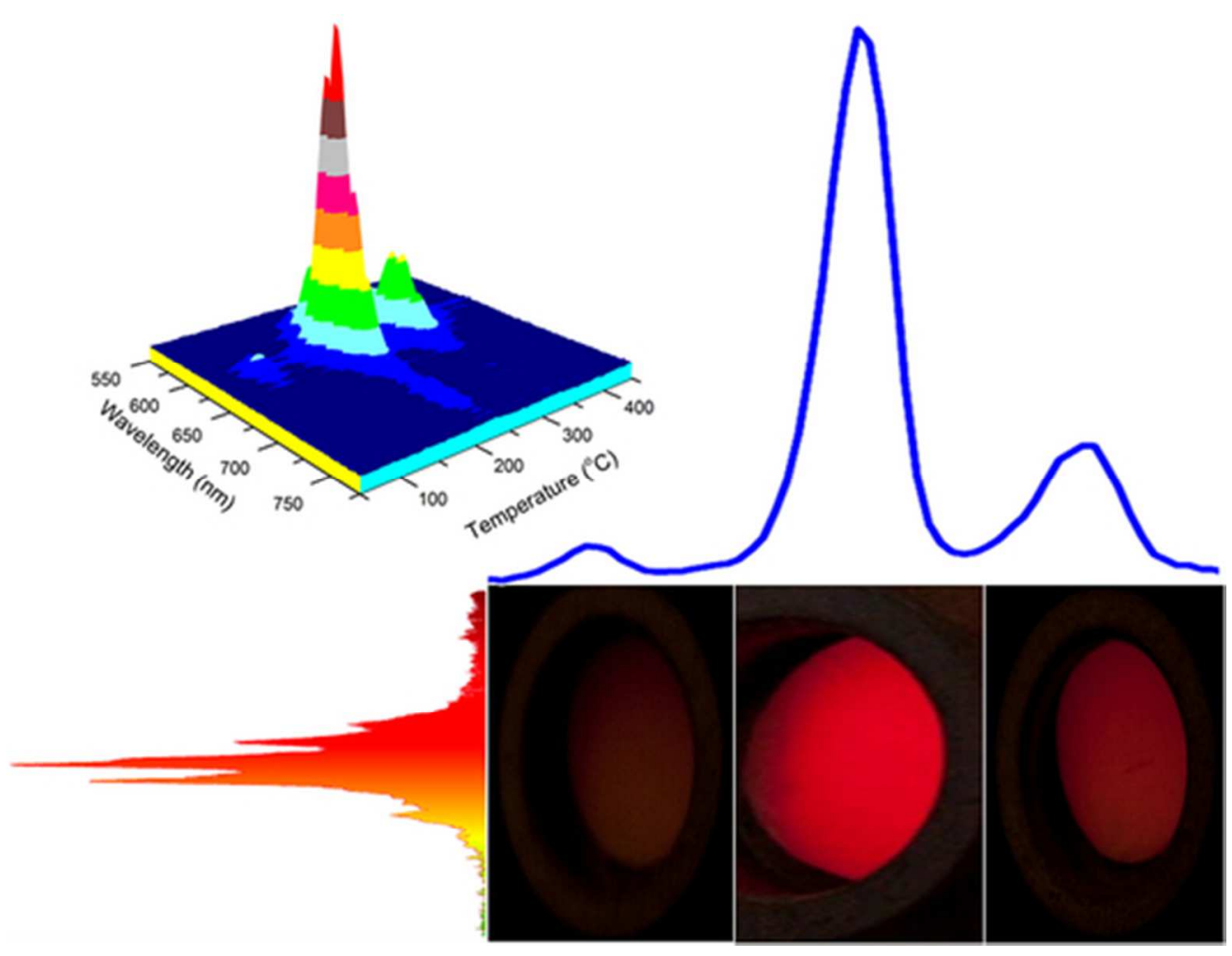

$44 \times 34 \mathrm{~mm}(300 \times 300 \mathrm{DPI})$ 